\title{
Dual-phase nanostructuring as a route to flexible nanoporous metals with outstanding comprehensive mechanical properties
}

\author{
Chaoyang Wang ${ }^{1}$, Zhangyi $\mathrm{Li}^{1}$, Shengli Zhu ${ }^{1,2,4^{*}}$, Yanqin Liang ${ }^{1,2}$, Zhenduo Cui ${ }^{1}$, Shuilin $\mathrm{Wu}^{1,2}$, \\ Chunling Qin ${ }^{3}$, Shuiyuan Luo ${ }^{4}$ and Akihisa Inoue ${ }^{1,5^{*}}$
}

\begin{abstract}
The mechanical properties of nanoporous metals (NPMs) are very important for their potential applications in flexible electronics. Here, the NP Cu@Zr-Cu-Al metallic glass (NP Cu@Zr-Cu-Al MG) composite with high strength, high hardness, and good flexibility is reported. The NP $\mathrm{Cu@Zr-Cu-Al} \mathrm{MG} \mathrm{was} \mathrm{synthesized} \mathrm{by} \mathrm{a} \mathrm{two-step} \mathrm{dealloying}$ method. First, the flexible NP $\mathrm{Zr}$-Cu-Al MG was prepared by selective etching the active $\mathrm{Y}$-rich MG from the pseudobinary MG system ( $\left.\mathrm{Zr}_{47} \mathrm{Cu}_{46} \mathrm{Al}_{7} \mathrm{MG}+\mathrm{Y}_{47} \mathrm{Cu}_{46} \mathrm{Al}_{7} \mathrm{MG}\right)$ of $\mathrm{Cu}_{46} \mathrm{Zr}_{23.5^{-}}$ $\mathrm{Y}_{23.5} \mathrm{Al}_{7}$ alloy. The NP Cu@Zr-Cu-Al MG was then obtained by further etching the NP $\mathrm{Zr}-\mathrm{Cu}-\mathrm{Al}$ MG and the $\mathrm{Cu}$ layer was evenly covered on the MG matrix of ligaments. The NP $\mathrm{Cu} @ \mathrm{Zr}-\mathrm{Cu}-\mathrm{Al}$ MG demonstrated good flexibility due to its non-cracking structure and the existence of flexible $\mathrm{Zr}$ - $\mathrm{Cu}$-Al MG. Additionally, the NP Cu@Zr-Cu-Al MG showed the highest tensile strength of 143.9 MPa and nanohardness of $0.79 \mathrm{GPa}$ among all the reported NPMs. The $\mathrm{Zr}-\mathrm{Cu}-\mathrm{Al}$ MG strengthening phase weakened the rupture of $\mathrm{Cu} @ \mathrm{Zr}-\mathrm{Cu}-\mathrm{Al}$ ligaments, which could effectively restrain the crack initiation and propagation in the NP Cu@Zr-Cu-Al MG. Finally, it could improve the comprehensive mechanical properties. The NP $\mathrm{Cu} @ \mathrm{Zr}-\mathrm{Cu}-\mathrm{Al}$ MG was applied as an electrode for supercapacitors and glucose biosensors. The NP Cu@Zr-Cu-Al MG electrode displayed better conductivity and supercapacitor capacitance than the bare NP $\mathrm{Zr}$-Cu-Al MG electrode.
\end{abstract}

Keywords: nanoporous metals, metallic glass, mechanical properties, nanoindentation, flexible electrodes

\section{INTRODUCTION}

Flexible electronics have acquired immense popularity since the rapid development of wearable equipment and biomedical devices, such as the roll-up displays, smartwatches, portable screen, artificial electronic skin, and implantable medical biosensors [1-3]. The flexible electrodes are the key parts of such devices; they could act as the power source units for bendable electronic screens and the biosensor components for wearable healthcare monitoring [4,5]. Therefore, one of the critical challenges for flexible electronics is to design and synthesize the reliable, flexible electrode materials with good electrochemical performance, robust flexibility, and with ultrathin and lightweight characteristics $[1,3,4]$.

In recent years, nanoporous metals (NPMs) such as NP $\mathrm{Cu}$ [6], Ni [7], Au [8], Ag [9], Pd [10], and Pt [11] have attracted attention for lithium-ion batteries, biosensors, and supercapacitors, owing to their excellent energy storage performance and electrocatalytic properties [6-11]. However, these NPMs usually possess macroscopic fragility, which can damage the physicochemical stability and reliability. The brittleness of NPMs also limits their potential applications in flexible electronics. Therefore, it is challenging to synthesize NPMs with good flexibility. Additionally, NPMs often exhibit relatively low tensile strength due to their irregular open-cell structures $[12,13]$. The NPMs usually show irregular distributions of ligament shape, size, and surface curvature. Hence, the tensile stress is concentrated on the weak ligaments of

\footnotetext{
${ }^{1}$ School of Materials Science and Engineering, Tianjin University, Tianjin 300072, China

${ }^{2}$ Tianjin Key Laboratory of Composite and Functional Materials, Tianjin 300072, China

${ }^{3}$ School of Materials Science and Engineering, Hebei University of Technology, Tianjin 300130, China

${ }^{4}$ College of Chemistry Engineering and Materials Science, Quanzhou Normal University, Quanzhou 362000, China

${ }^{5}$ Department of Physics, King Abdulaziz University, Jeddah 22254, Saudi Arabia

* Corresponding authors (emails: slzhu@tju.edu.cn (Zhu S); inoue@jiu.ac.jp (Inoue A))
} 
NPMs under an external force. Once the weakest ligaments are ruptured, the stress concentration quickly increases at their neighbouring ligaments, leading to the sequential rupturing and rapid propagation of microcracks $[12,14]$. Some reports investigated the mechanical properties of the NPMs using various techniques: compression and tension testing of millimeter-sized samples [15,16], micro-pillar compression [17], Vickers hardness, and nanoindentation measurements $[18,19]$. The studies on NP Au and Ag [20,21] demonstrated that the mechanical properties of NPMs could be related to the Gibson-Ashby (G-A) scaling laws [22], which were initially established for the conventional porous materials with low density and irregular open-cell structure on a millimetre or micrometre scale. However, Liu et al. [23] reported that the strength of NP Au predicted by G-A scaling laws was considerably larger than the actual values. It was attributed to imperfect connectivity within NP $\mathrm{Au}$ owing to noncontribution of the non-connected $\mathrm{Au}$ ligaments to the instant strength under the external load $[21,23]$. A modified G-A scaling equation has been constructed by introducing an effective relative density $\left(\varphi_{\text {eff }}\right)$ [23]:

$\sigma_{\text {nanoporous }}=0.3 \sigma_{\text {solid }} \phi_{\text {eff }}^{3 / 2}$,

where $\sigma_{\text {nanoporous }}$ and $\sigma_{\text {solid }}$ are the strengths of NPMs and the solid ligaments, respectively. The effective relative density $\left(\varphi_{\text {eff }}\right)$ only denotes the volume fraction of interconnected solid ligaments that can sense and respond to the external load. According to modified G-A scaling equation, there are two methods for increasing the mechanical strength of NPMs: (1) optimising the connectivity of solid ligaments in NPMs to improve the value of $\varphi_{\text {eff }}$ and (2) enhancing the intrinsic strength of the solid ligaments in NPMs to improve the value of $\sigma_{\text {solid. }}$.

The precursor alloys with uniform dual phases are dealloyed to form the well-interconnected solid ligaments structure [21]. This is because nanopores are formed only via a simple excavation of extra phases of polycrystalline master alloys; they do not form via a complex atomic reconstruction process, which involves rebuilding an open-cell nanoporous structure through surface diffusion. In our previous work, the significantly continuous NP Ag metals with good ligament connectivity were fabricated by dealloying the bi-phased $\mathrm{Cu}-\mathrm{Ag}$-La alloy precursors [21]. The well-interconnected NP Ag samples exhibited a high $\varphi_{\text {eff }}$ of 0.407 , while the $\varphi_{\text {eff }}$ of the ill-interconnected NPMs was as low as 0.147. Therefore, the NP Ag samples with good connectivity had large tensile strength of $68 \mathrm{MPa}$ and nanohardness of $0.206 \mathrm{GPa}$, which are much higher than those of reported NP Au and Ag materials with poor connectivity [21,23]. Additionally, the improvement of the intrinsic strength of the ligaments was also reported. Gwak et al. [20] fabricated the twinned NP $\mathrm{Au}$ with a tensile strength of $87.5 \mathrm{MPa}$, which was approximately three times greater than that of NP Au with rare twins. It indicated that internal defects and strengthening phases could act as effective barriers to obstruct dislocation motion, and further enhance the macroscopic strength [24-26]. Two important aspects should be considered to enhance the intrinsic strength of the ligaments: (1) type of reinforcements to be selected and (2) ways to embed the reinforcements in the ligaments.

Metallic glass (MG) is considered as appropriate reinforcement due to its superior high fracture toughness, high mechanical strength, and good elastic behaviour $[27,28]$. Many studies have focused on the $\mathrm{Zr}$-Cu-based MG systems, such as $\mathrm{Zr}-\mathrm{Cu}-\mathrm{Al}, \mathrm{Zr}-\mathrm{Al}-\mathrm{Ni}-\mathrm{Cu}, \mathrm{Zr}-\mathrm{Ti}-\mathrm{Ni}-$ $\mathrm{Cu}-\mathrm{Be}$ and $\mathrm{Zr}-\mathrm{Cu}-\mathrm{Al}-\mathrm{Ag}$, due to their high glass-forming abilities and good mechanical properties $[29,30]$. Nevertheless, $\mathrm{Zr}$-Cu-based MG generally displays lower electrical conductivity than its crystalline counterpart owing to its disordered structures [31]. On the other hand, plenty of $\mathrm{Zr}$ and $\mathrm{Al}$ elements in $\mathrm{Zr}-\mathrm{Cu}$-based $\mathrm{MG}$ can influence the electrochemical behaviors owing to their poor chemical activity. Therefore, combining the advantages of both MG and NPMs, the NPMs@MG composite is considered to have good comprehensive performance.

The flexible NP Cu@Zr-Cu-Al MG composite was prepared by a two-step chemical dealloying method. It was observed to have larger tensile strength and nanohardness than pure NP Cu. Moreover, it showed better electrical conductivity than pure NP $\mathrm{Zr}-\mathrm{Cu}-\mathrm{Al} \mathrm{MG}$ alloy. Additionally, the composite exhibited good physicochemical properties and long-term stability. The flexible $\mathrm{NPCu@Zr-Cu-Al} \mathrm{MG} \mathrm{composite} \mathrm{is} \mathrm{a} \mathrm{promising} \mathrm{material}$ for micro-electromechanical systems-wearable healthcare and flexible electronic devices.

\section{EXPERIMENTAL SECTION}

\section{Synthesis method}

The alloy ingots with the composition of $\mathrm{Zr}_{47} \mathrm{Cu}_{46} \mathrm{Al}_{7}$ and $\mathrm{Y}_{47} \mathrm{Cu}_{46} \mathrm{Al}_{7}$ were prepared by arc-melting the mixtures of pure elements under argon atmosphere in a water-cooled $\mathrm{Cu}$ hearth. The master alloys were reversed and re-melted at least five times to ensure the uniformity of the alloy composition. The $\mathrm{Cu}_{46} \mathrm{Zr}_{23.5} \mathrm{Y}_{23.5} \mathrm{Al}_{7}$ ingots were prepared 
by mixing $\mathrm{Zr}_{47} \mathrm{Cu}_{46} \mathrm{Al}_{7}$ and $\mathrm{Y}_{47} \mathrm{Cu}_{46} \mathrm{Al}_{7}$ alloys with the weight ratio of 1:1.015 [27]. The MG ribbons were prepared by re-melting the ingots in a high-frequency induction furnace and rapidly ejecting them onto a rotating copper wheel with a linear velocity of $36.7 \mathrm{~m} \mathrm{~s}^{-1}$. The asformed $\mathrm{Cu}_{46} \mathrm{Zr}_{23.5} \mathrm{Y}_{23.5} \mathrm{Al}_{7}$ ribbon is a pseudobinary $\mathrm{MG}$, which is composed of $\mathrm{Zr}_{47} \mathrm{Cu}_{46} \mathrm{Al}_{7} \mathrm{MG}$ and $\mathrm{Y}_{47} \mathrm{Cu}_{46} \mathrm{Al}_{7}$ MG components [27,32]. The $\mathrm{Cu}_{46} \mathrm{Zr}_{23.5} \mathrm{Y}_{23.5} \mathrm{Al}_{7}$ ribbon samples with a size of $1.5 \mathrm{~mm} \times 25 \mu \mathrm{m} \times 3 \mathrm{~cm}$ (width $\times$ thickness $\times$ length) were immersed in the $0.1 \mathrm{~mol} \mathrm{~L}^{-1}$ $\mathrm{HNO}_{3}$ solution at $298 \mathrm{~K}$. The electrochemical etching of $\mathrm{Cu}_{46} \mathrm{Zr}_{23.5} \mathrm{Y}_{23.5} \mathrm{Al}_{7}$ ribbons were potentiostatically kept at $0.4 \mathrm{~V}(v s$. $(\mathrm{Ag} / \mathrm{AgCl}))$, controlled by an electrochemical workstation (Gamry Interface 1000). The etching potential was determined by thermodynamic and kinetic considerations of two $\mathrm{MG}$ components [27]. The $\mathrm{Zr}_{47} \mathrm{Cu}_{46} \mathrm{Al}_{7}$ MG is relatively inert compared with the $\mathrm{Y}_{47} \mathrm{Cu}_{46} \mathrm{Al}_{7} \mathrm{MG}$ owing to its quite lower anodic current density at the applied potential of $0.4 \mathrm{~V}$. Therefore, the $\mathrm{Y}_{47} \mathrm{Cu}_{46} \mathrm{Al}_{7} \mathrm{MG}$ can be electrochemically dissolved while the relatively stable $\mathrm{Zr}-\mathrm{Cu}-\mathrm{Al} \mathrm{MG}$ is retained as the skeletons of nanoporous structure (Fig. 1a). Thereafter, the NP $\mathrm{Zr}-\mathrm{Cu}-\mathrm{Al}$ MG ribbons were rinsed with deionized water five times, and then further dealloyed in the $0.2 \mathrm{~mol} \mathrm{~L}^{-1} \mathrm{HF}$ acid solution at $298 \mathrm{~K}$. Finally, the ribbons were well rinsed with deionized water and alcohol to remove the residual
HF solutions, and then dried in a vacuum chamber. The control sample of NP $\mathrm{Cu}$ was prepared by dealloying the $\mathrm{Zr}_{47} \mathrm{Cu}_{46} \mathrm{Al}_{7} \mathrm{MG}$ ribbons in the $0.05 \mathrm{~mol} \mathrm{~L}^{-1} \mathrm{HF}$ acid solution at $298 \mathrm{~K}$ [33]. The preparation conditions were similar to those of $\mathrm{Cu}_{46} \mathrm{Zr}_{23.5} \mathrm{Y}_{23.5} \mathrm{Al}_{7}$ alloy.

\section{Characterization}

The crystal structure was characterized by X-ray diffraction (XRD, Bruker D8) using the $\mathrm{Cu} \mathrm{Ka}$ radiation. The morphology, microstructure, and composition were examined using a scanning electron microscope (SEM, Hitachi S-4800) and a transmission electron microscope (TEM, JEOL JEM-2010F) coupled with energy-dispersive $\mathrm{X}$-ray spectroscopy (EDS). The nitrogen $\left(\mathrm{N}_{2}\right)$ adsorptiondesorption isotherms and pore size were measured using a BELSORP-max (MP) Brunauer-Emmett-Teller (BET, Micromeritics TriStar II 3020) surface analyser. Differential scanning calorimetry (DSC) experiments were performed with a METTLER TOLEDO STD1600 instrument under a purified argon atmosphere at a heating rate of $0.67 \mathrm{~K} \mathrm{~s}^{-1}$.

\section{Property measurement}

Tensile tests were performed using an Instron mechanical testing machine equipped with an electronic strain gauge at a strain rate of $5.0 \times 10^{-4} \mathrm{~s}^{-1}$. The gauge dimension of
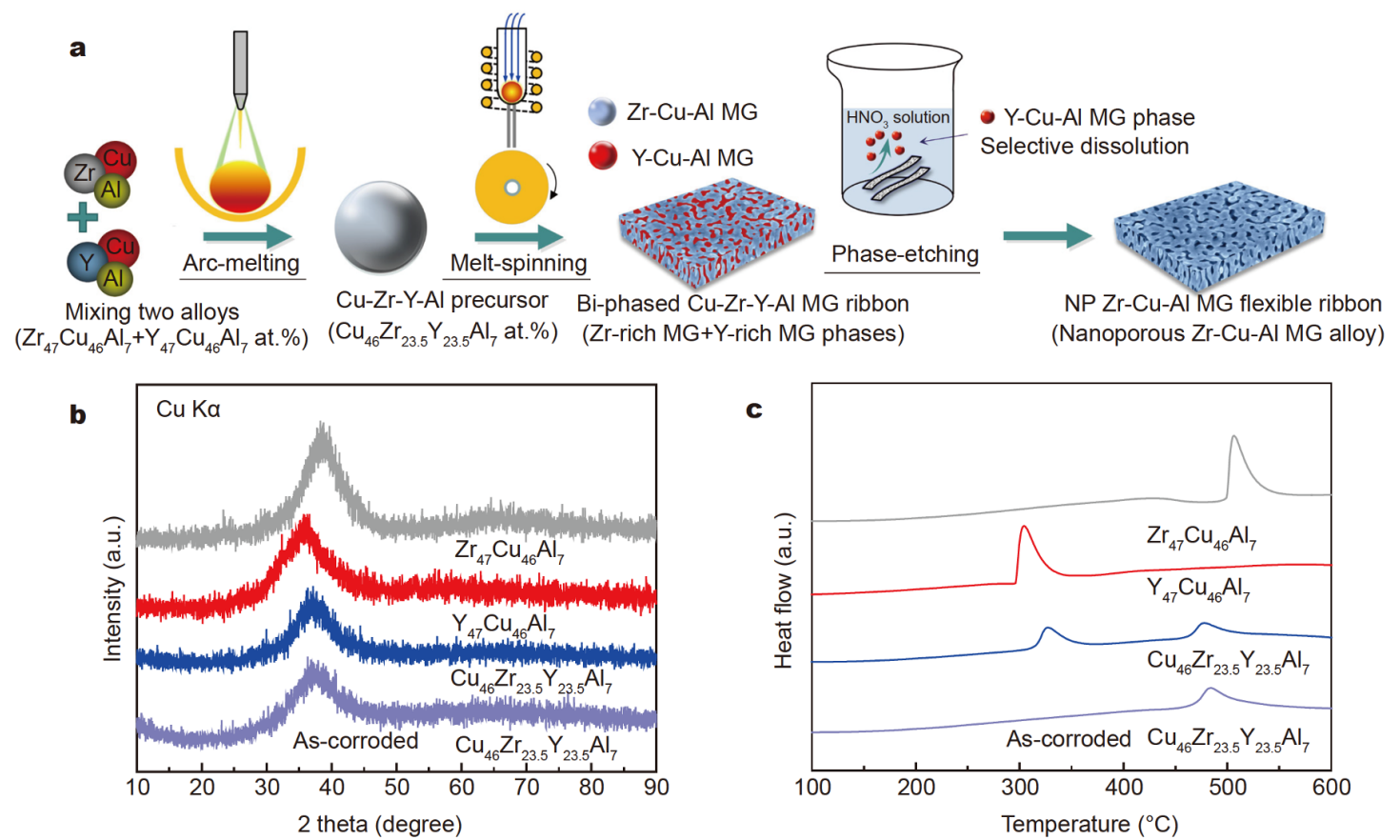

Figure 1 (a) Schematic illustration of the fabrication process of NP $\mathrm{Zr}-\mathrm{Cu}-\mathrm{Al} \mathrm{MG}$ ribbons by selective etching $\mathrm{Cu}_{46} \mathrm{Zr}_{23.5} \mathrm{Y}_{23.5} \mathrm{Al}_{7}$ alloy ribbon. (b) XRD patterns and (c) DSC curves of $\mathrm{Cu}_{46} \mathrm{Zr}_{23.5} \mathrm{Y}_{23.5} \mathrm{Al}_{7}$ alloy ribbons before and after electrochemical etching. 
tensile test specimens was $1 \mathrm{~cm} \times 17 \mu \mathrm{m} \times 1.5 \mathrm{~mm}$ (length $\times$ thickness $\times$ width). Nanomechanical property was examined by a Nano Indenter (Hysitron TI-Premier) with loading and displacement resolutions of $50 \mathrm{nN}$ and $0.01 \mathrm{~nm}$, respectively. More than ten nanoindentation tests were conducted on each specimen. Moreover, the bending flexibility was evaluated using a simple bend test.

The supercapacitor performance was investigated by galvanostatic charge-discharge (GCD) and cyclic voltammetry (CV) tests. Additionally, the glucose biosensor property was also measured using CV tests. Moreover, the electrical conductivity was detected by electrochemical impedance spectroscopy (EIS) tests. These electrochemical tests were performed on an electrochemical working station (Gamry Interface 1000). The electrochemical tests were performed in a three-electrode system at $298 \mathrm{~K}$ using the platinum foil $(1.5 \mathrm{~cm} \times 1.5 \mathrm{~cm})$ as the counter electrode and $\mathrm{Ag} / \mathrm{AgCl}$ reference electrode. The $0.2 \mathrm{~mol} \mathrm{~L}^{-1} \mathrm{NaOH}$ alkaline solution was used as the electrolyte.

\section{RESULTS AND DISCUSSIONS}

\section{Fabrication and microstructure of NP Zr-Cu-Al MG}

The NP $\mathrm{Zr}-\mathrm{Cu}-\mathrm{Al} \mathrm{MG}$ was prepared by etching the pseudobinary $\mathrm{Cu}_{46} \mathrm{Zr}_{23.5} \mathrm{Y}_{23.5} \mathrm{Al}_{7} \mathrm{MG}\left(\mathrm{Zr}_{47} \mathrm{Cu}_{46} \mathrm{Al}_{7} \mathrm{MG}+\right.$ $\left.\mathrm{Y}_{47} \mathrm{Cu}_{46} \mathrm{Al}_{7} \mathrm{MG}\right)$ in $0.01 \mathrm{~mol} \mathrm{~L}^{-1} \mathrm{HNO}_{3}$ acid solution for $500 \mathrm{~s}[27,32]$. The electrochemical etching of $\mathrm{Cu}_{46} \mathrm{Zr}_{23.5^{-}}$ $\mathrm{Y}_{23.5} \mathrm{Al}_{7} \mathrm{MG}$ ribbons was potentiostatically conducted at $0.4 \mathrm{~V}(v s .(\mathrm{Ag} / \mathrm{AgCl}))$, controlled by an electrochemical workstation (Gamry Interface 1000). This etching potential was determined by considering the thermodynamic and kinetic properties of the two MG components [27]. The $\mathrm{Zr}_{47} \mathrm{Cu}_{46} \mathrm{Al}_{7} \quad \mathrm{MG}$ is relatively inert than $\mathrm{Y}_{47} \mathrm{Cu}_{46} \mathrm{Al}_{7} \mathrm{MG}$ because of its lower anodic current density at the applied potential of $0.4 \mathrm{~V}$. Hence, the $\mathrm{Y}_{47} \mathrm{Cu}_{46} \mathrm{Al}_{7} \mathrm{MG}$ can be electrochemically dissolved while the relatively stable $\mathrm{Zr}-\mathrm{Cu}-\mathrm{Al} \mathrm{MG}$ is retained as the skeletons of nanoporous structure, as schematically depicted in Fig. 1a. The glassy nature was verified by XRD patterns (Fig. 1b). Each XRD pattern of the $\mathrm{Y}_{47} \mathrm{Cu}_{46} \mathrm{Al}_{7}$, $\mathrm{Zr}_{47} \mathrm{Cu}_{46} \mathrm{Al}_{7}$ and $\mathrm{Cu}_{46} \mathrm{Zr}_{23.5}-\mathrm{Y}_{23.5} \mathrm{Al}_{7}$ ribbons shows a characteristic broad halo with the absence of crystalline peak, indicating a glassy structure. During the etching process, the active $\mathrm{Y}-\mathrm{Cu}-\mathrm{Al} \mathrm{MG}$ was selectively dissolved from the pseudobinary $\mathrm{Cu}-\mathrm{Zr}-\mathrm{Y}-\mathrm{Al} \mathrm{MG}$ precursors, while the relatively stable $\mathrm{Zr}$-Cu-Al MG was retained [27]. Therefore, the as-corroded $\mathrm{Cu}-\mathrm{Zr}$-Y-Al MG still exhibited the characteristic broad XRD pattern after the selective etching (Fig. 1b). The result is further supported by the
DSC curves (Fig. 1c). The DSC trace of pseudobinary $\mathrm{Cu}-$ $\mathrm{Zr}-\mathrm{Y}$-Al MG precursor is divided into two exothermic crystallisation peaks, which are well consistent with crystallisation peaks of $\mathrm{Zr}-\mathrm{Cu}-\mathrm{Al} \mathrm{MG}$ and $\mathrm{Y}-\mathrm{Cu}-\mathrm{Al} \mathrm{MG}$. In the solid state, the $\mathrm{Zr}-\mathrm{Cu}-\mathrm{Al}$ and $\mathrm{Y}-\mathrm{Cu}-\mathrm{Al}$ are immiscible in the $\mathrm{Cu}-\mathrm{Zr}-\mathrm{Y}-\mathrm{Al}$ alloy system because of the presence of large miscibility gap between $\mathrm{Zr}$-rich and Yrich glass components owing to the positive mixing heat $\left(+35 \mathrm{~kJ} \mathrm{~mol}^{-1}\right)$ between $\mathrm{Zr}$ and $\mathrm{Y}$ elements [32]. After etching, the crystallisation peak of the Y-rich MG disappeared, while that of the Zr-rich MG remained. It indicates that the active $Y$-rich MG was removed, while the residual Zr-rich MG built nanoporous skeletons. Nevertheless, the as-corroded $\mathrm{Cu}-\mathrm{Zr}-\mathrm{Y}-\mathrm{Al} \mathrm{MG}$ revealed a lower heat capacity for the exothermic reaction than the $\mathrm{Zr}-\mathrm{Cu}$ $\mathrm{Al} \mathrm{MG}$, possibly due to the surface passivation of the ascorroded Cu-Zr-Y-Al MG [27].

The morphology of the as-corroded $\mathrm{Cu}-\mathrm{Zr}-\mathrm{Y}-\mathrm{Al} \mathrm{MG}$ is shown in Fig. 2. The cross-sectional image in Fig. 2a shows that the three-dimensional (3D), well-interconnected nanoporous structure uniformly spans the thickness of the sample. Meanwhile, the surface image in Fig. $2 \mathrm{~b}$ also reveals the good ligament/pore morphology with the desirable network connectivity. The microstructural characteristics of the sample were further investigated. The TEM image in Fig. $2 \mathrm{c}$ shows the nanoporous structure, which is consistent with the SEM results. The selected area electron diffraction (SAED) pattern (inset of Fig. 2c) and high-resolution TEM image confirm the glassy state of the sample. TEM-EDS measured the composition of the skeletons in the nanoporous structure. The $\mathrm{Y}$ element almost disappeared, and $\mathrm{Cu}$ content decreased compared with the chemical composition of the $\mathrm{Cu}-\mathrm{Zr}-\mathrm{Y}-\mathrm{Al}$ MG precursor (Fig. S1), indicating that the nanopore structure originated from the selective dissolution of the active Y-Cu-Al MG component [27]. Furthermore, the EDS mapping shows that the $\mathrm{Cu}, \mathrm{Zr}$, and $\mathrm{Al}$ elements are uniformly and spatially distributed within the glassy skeleton, which straightforwardly proves the formation of $\mathrm{NP} \mathrm{Zr}-\mathrm{Cu}-\mathrm{Al}$ MG (Fig. 2d). These results also suggest that the porous structure is determined by the original structure of the pseudobinary (Zr-Cu-Al MG + Y-Cu-Al MG) Cu-Zr-Y$\mathrm{Al}$ MG precursor alloy, while the porous structure and porosity can be tailored by tuning the relative ratio of the two MG compositions in the precursors [27]. The NP Zr$\mathrm{Cu}-\mathrm{Al} \mathrm{MG}$ exhibited a large specific surface area of $58.24 \mathrm{~m}^{2} \mathrm{~g}^{-1}$ and high porosity percentage of $47 \%$ (Fig. 2e). The size of nanopores mainly ranged from 10 to $30 \mathrm{~nm}$, and the average pore diameter was $10.66 \mathrm{~nm}$ 

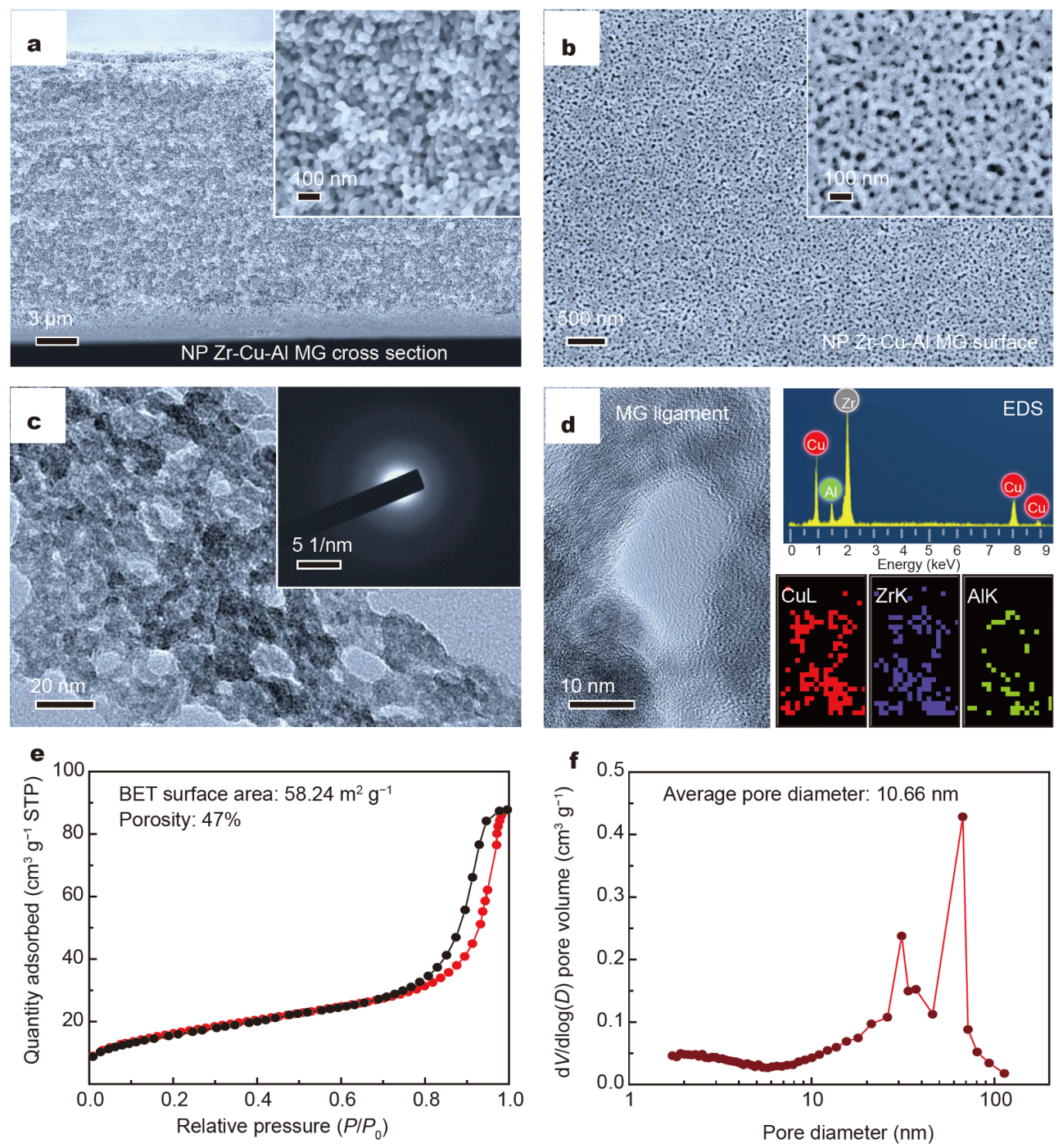

Figure 2 Structural characterization of the NP Zr-Cu-Al MG alloy. (a, b) Cross-sectional and surface SEM images. (c) TEM image and SAED pattern. (d) High-resolution TEM image and EDS mapping. (e, f) $\mathrm{N}_{2}$ adsorption/desorption isotherms and pore size distribution.

(Fig. 2f).

\section{Mechanical properties of NP Zr-Cu-Al MG}

The mechanical properties of the NP $\mathrm{Zr}-\mathrm{Cu}-\mathrm{Al}$ MG were measured through the nanoindentation and macroscopic tension tests. Fig. 3a shows the nanoindentation forcedepth curves under different loads. Fig. 3b shows the dependence curves of nanohardness $(H)$ and Young's modulus $(E)$ on the indentation depth. The $H$ and $E$ of the NP Zr-Cu-Al MG under different indentation depths are approximately 1.27 and $23.7 \mathrm{GPa}$, respectively. The increment in indentation depth has little influence on the nanomechanical properties, indicating the good mechanical stability under external force loading. The NP
$\mathrm{Zr}-\mathrm{Cu}-\mathrm{Al} \mathrm{MG}$ ribbon can be readily shaped into any desired forms without breaking it (insets of Fig. 3b); owing to the excellent bending ductility of MG [34]. Fig. $3 \mathrm{c}-\mathrm{g}$ show the scanning probe microscopy (SPM) images of the NP $\mathrm{Zr}-\mathrm{Cu}-\mathrm{Al}$ MG subjected to different indentation depths, as shown in Fig. 3a. Stress cracking did not exist even at the indentation depth of $1234 \mathrm{~nm}$, suggesting good mechanical integrity during deformation. Fig. $3 \mathrm{~h}$ shows a typical tensile stress-strain curve of the NP $\mathrm{Zr}-\mathrm{Cu}-\mathrm{Al} \mathrm{MG}$ ribbon. The NP $\mathrm{Zr}-\mathrm{Cu}-\mathrm{Al} \mathrm{MG}$ showed the high fracture tensile strength of $240.7 \mathrm{MPa}-$ approximately ten times higher than most of the reported NPMs [21,23,35-37]. The superior strength of NP Zr-Cu$\mathrm{Al} \mathrm{MG}$ was derived from the extremely high strength of 

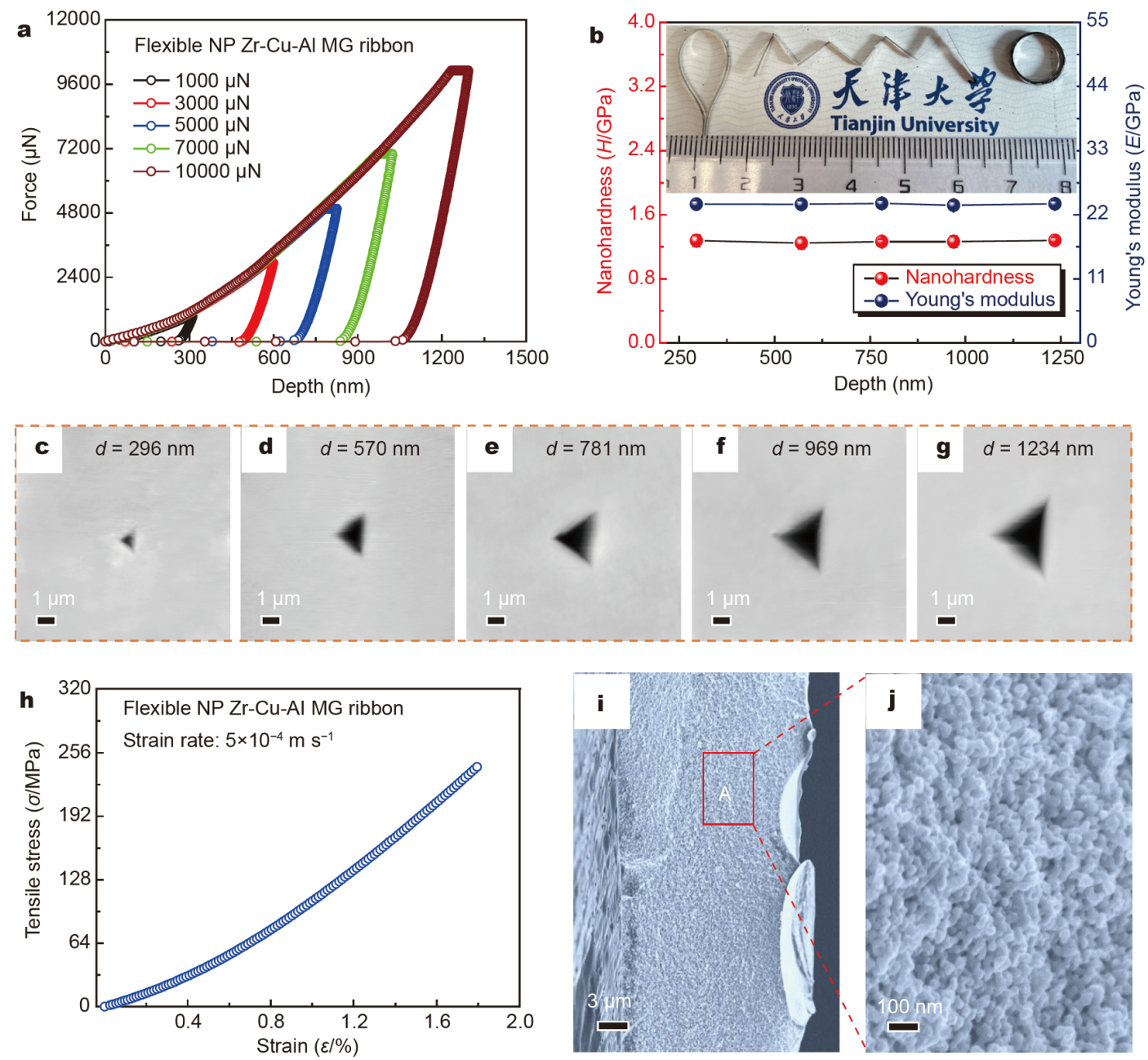

Figure 3 Mechanical measurements of the NP Zr-Cu-Al MG alloy. (a) The nanoindentation force-depth curves and (b) the nanomechanical properties as a function of indentation depth. (c-g) SPM images as a function of indentation depth for the indentation traces. (h) Tensile stress-strain curves. (i, g) The fracture morphologies of porous ribbon samples subjected to tension testing.

the $\mathrm{Zr}-\mathrm{Cu}-\mathrm{Al} \mathrm{MG}$, which is significantly higher than that of crystalline $\mathrm{Au}, \mathrm{Ag}, \mathrm{Cu}$, and $\mathrm{Pt}$ metals. The fracture surface of the $\mathrm{NP} \mathrm{Zr}-\mathrm{Cu}-\mathrm{Al} \mathrm{MG}$ ribbon subjected to the tensile fracture is shown in Fig. $3 \mathrm{i}$ and $\mathrm{j}$. They show that the ligaments of $\mathrm{NP} \mathrm{Zr}-\mathrm{Cu}-\mathrm{Al} \mathrm{MG}$ are uniformly deformed on the fracture surface.

\section{Fabrication and microstructure of NP Cu@Zr-Cu-Al MG composite}

The NP $\mathrm{Zr}-\mathrm{Cu}-\mathrm{Al} \mathrm{MG}$ was etched in $0.2 \mathrm{~mol} \mathrm{~L}^{-1} \mathrm{HF}$ solution at $298 \mathrm{~K}$. Many gas bubbles were formed on the sample surface during the immersion, suggesting that the $\mathrm{Zr}$ and $\mathrm{Al}$ elements were leached out of the $\mathrm{NP} \mathrm{Zr}-\mathrm{Cu}-\mathrm{Al}$ MG. After etching for $1000 \mathrm{~s}$, the formation of gas bubbles was stopped. Moreover, the colour of the NP $\mathrm{Zr}-\mathrm{Cu}-$
Al MG changed from argentous to a typical $\mathrm{Cu}$ metallic lustre. The XRD patterns of as-dealloyed NP $\mathrm{Zr}-\mathrm{Cu}-\mathrm{Al}$ $M G$ revealed the sharp diffraction peaks of face-centered cubic ( $\mathrm{fcc}$ ) $\mathrm{Cu}$ crystalline phase [38] that were superimposed on the board amorphous halo peak of NP Zr$\mathrm{Cu}-\mathrm{Al} \mathrm{MG}$ (Fig. 4a). This result indicates that fcc $\mathrm{Cu}$ metal was formed on the $\mathrm{Zr}-\mathrm{Cu}-\mathrm{Al}$ MG by selectively dissolving the active $\mathrm{Zr}$ and $\mathrm{Al}$ elements in $\mathrm{HF}$ solution $[33,38]$. The sample of $\mathrm{NP} \mathrm{Cu}$ plus $\mathrm{Zr}-\mathrm{Cu}-\mathrm{Al} \mathrm{MG}$ is named NPCu@Zr-Cu-Al MG composite. Moreover, the cross-section of the NP Cu@Zr-Cu-Al MG composite ribbon showed the bicontinuous ligament-channel nanostructure (Fig. 4b). TEM image (Fig. 4c) shows the nanoporous morphology with the ligament size approximately $10 \mathrm{~nm}$. In the SAED pattern (inset of Fig. 4c), 

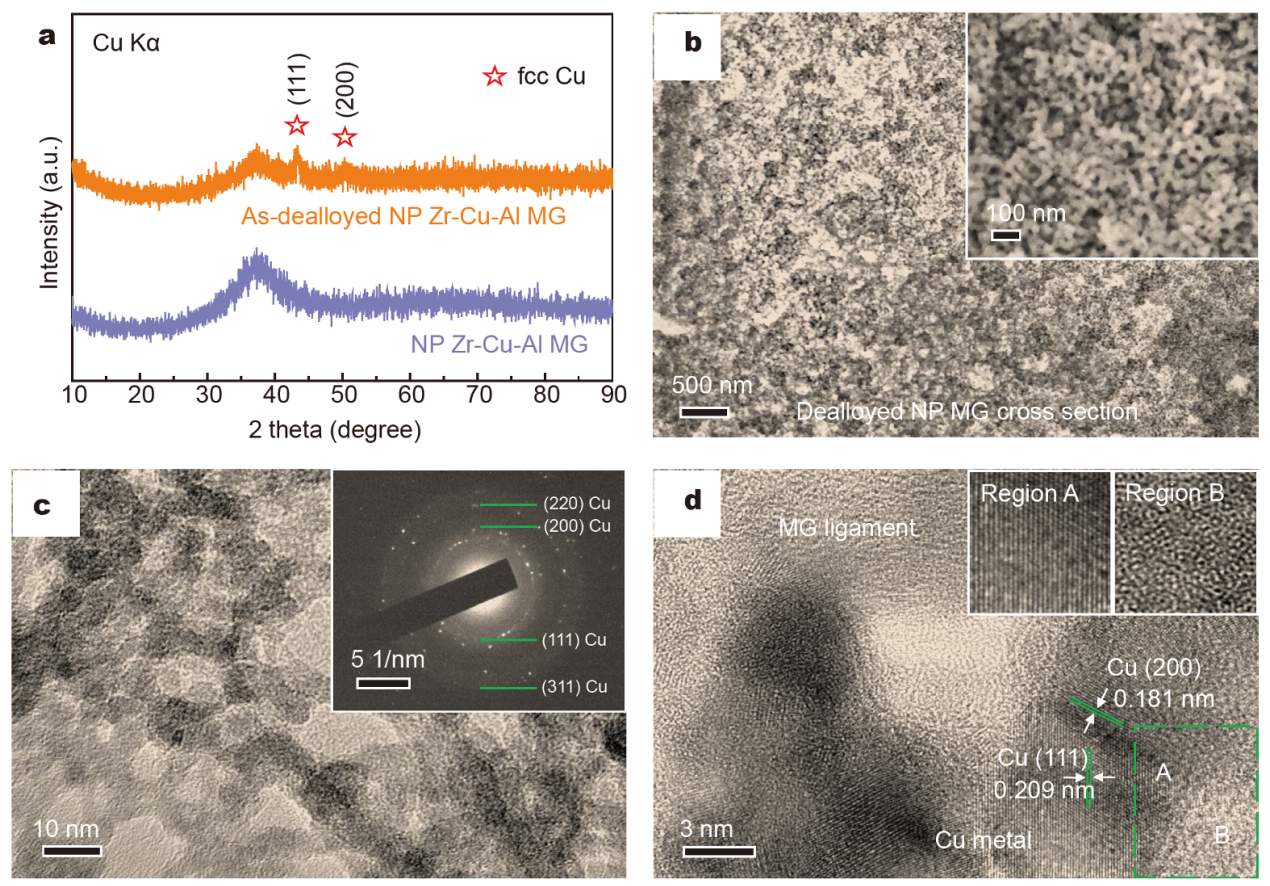

$$
\text { e }
$$
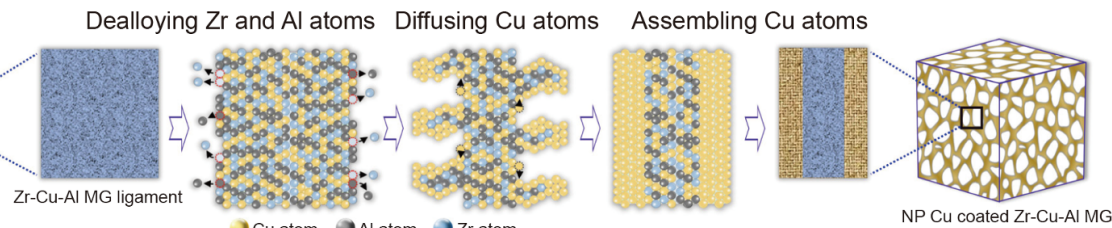

Figure 4 Structural characterization of the NP Cu@Zr-Cu-Al MG hybrid alloy. (a) XRD patterns of NP Zr-Cu-Al MG alloy before and after dealloying. (b) Cross-sectional SEM images. (c) TEM images and SAED pattern. (d) High-resolution TEM images. (e) Schematic illustration showing the formation mechanism of NP Cu@Zr-Cu-Al MG hybrid alloy during dealloying the NP Zr-Cu-Al MG in HF acid solution.

the characteristic amorphous halo pattern of $\mathrm{Zr}-\mathrm{Cu}-\mathrm{Al}$ MG is superimposed with the polycrystal diffraction pattern of fcc $\mathrm{Cu}$ crystalline phase. High-resolution TEM image (Fig. 4d) shows the mixed phases of crystal $\mathrm{Cu}$ lattice fringes and disordered glassy structure of NP Zr$\mathrm{Cu}-\mathrm{Al} \mathrm{MG}$ ligaments. The EDS mapping images (Fig. S2a-d) of individual elements in the TEM image (region $\mathrm{C}$ of Fig. S2a) display the enriched $\mathrm{Cu}$ layer on the ligaments. The ratio of $\mathrm{Cu} / \mathrm{Zr} / \mathrm{Al}$ atoms in NP $\mathrm{Cu} @ \mathrm{Zr}$ $\mathrm{Cu}-\mathrm{Al} \mathrm{MG}$ was 68:28:4 (Fig. S3); it had higher $\mathrm{Cu}$ content than that of NP $\mathrm{Zr}-\mathrm{Cu}-\mathrm{Al} \mathrm{MG}$ having $\mathrm{Cu} / \mathrm{Zr} / \mathrm{Al}$ atom ratio of 46:47:7, indicating the formation of $\mathrm{Cu}$ layer on the NP Zr-Cu-Al MG ligament. The BET results (Fig. S4) show that the as-prepared NP Cu@Zr-Cu-Al MG consisted of a large specific surface area of $41.6 \mathrm{~m}^{2} \mathrm{~g}^{-1}$ and a large porosity percentage of $55 \%$. Additionally, the average pore diameter of the NP Cu@Zr-Cu-Al MG composite was approximately $15.89 \mathrm{~nm}$, which is larger than that of $\mathrm{NP} \mathrm{Zr}-\mathrm{Cu}-\mathrm{Al} \mathrm{MG}$. The increment in pore size after NP Zr-Cu-Al MG etching leads to the decrement in specific surface area.

Fig. 4e schematically illustrates the formation process of the NPCu@Zr-Cu-Al MG composite. Similar to the dealloying process of monolithic $\mathrm{Zr}$ - $\mathrm{Cu}-\mathrm{Al}$ glassy ribbons $[33,39]$ or bulk $\mathrm{Zr}-\mathrm{Cu}-\mathrm{Al}$ metallic glass rods [38], the dealloying of $\mathrm{NP} \mathrm{Zr}-\mathrm{Cu}-\mathrm{Al} \mathrm{MG}$ starts from the outer surface of the MG ligaments. The active $\mathrm{Zr}$ and $\mathrm{Al}$ atoms were selectively dissolved from the ligaments due to the massive difference in the chemical stability between $\mathrm{Cu}$ and other two elements in the HF solution [33], leading to many vacancies on the surface of ligaments. Moreover, the residual noble $\mathrm{Cu}$ atoms moved along the interface between the ligaments and the HF solution; they then assembled to minimize the total surface and interfacial free energy $[21,40]$. After that, the $\mathrm{Cu}$-rich layer was formed on the surface of $\mathrm{Zr}-\mathrm{Cu}-\mathrm{Al} \mathrm{MG}$ ligaments. The possible formation mechanism of the $\mathrm{Cu}$-coated MG ligaments structure is proposed. First, unlike the solid thin 
film or ribbon precursors, the dealloying of $\mathrm{NP} \mathrm{Zr}-\mathrm{Cu}-\mathrm{Al}$ MG started from the outer surface of the nano-sized rodlike ligaments, and gradually evolved into the inner ligament matrices. It reduced the surface area between the inner and outer part of the MG ligaments. The specific surface area before and after dealloying the $\mathrm{NP} \mathrm{Zr}-\mathrm{Cu}-\mathrm{Al}$ MG was 58.24 and $41.6 \mathrm{~m}^{2} \mathrm{~g}^{-1}$, respectively (Fig. 2e and Fig. S4). Therefore, a large number of residual noble $\mathrm{Cu}$ atoms moved on the surface of these gradually shrinking rod-like MG ligaments, and preferentially assembled together to form an entire $\mathrm{Cu}$ coating on the ligament matrices.

The control sample of the NP $\mathrm{Cu}$ was prepared by dealloying the melt-spun $\mathrm{Zr}_{47} \mathrm{Cu}_{46} \mathrm{Al}_{7}$ MG ribbon in the $0.05 \mathrm{~mol} \mathrm{~L}^{-1} \mathrm{HF}$ acid solution for $5 \mathrm{~h}$ at $298 \mathrm{~K}$. The SEM images revealed the hierarchical architecture with homogeneous bicontinuous ligament/pore morphology (Fig. S5a-c). The ligament and pore sizes were approximately 35 and $30 \mathrm{~nm}$, respectively. The XRD and EDS results confirmed the pure fcc $\mathrm{Cu}$ phase of the ligament (Fig. S5b and d). The NP Cu had a large specific surface area of $41.04 \mathrm{~m}^{2} \mathrm{~g}^{-1}$ and porosity of $56 \%$ (Fig. S5e).

\section{Mechanical properties of NP Cu@Zr-Cu-Al MG composite} The tensile stress-strain curves are shown in Fig. 5a. Though further dealloying resulted in the reduction of the tensile strength, the NP Cu@Zr-Cu-Al MG still displayed a high tensile strength of $143.9 \mathrm{MPa}$, which was considerably higher than that of all the reported nanoporous pure metals $[21,23,35,36]$. The tensile strength of NP Cu in present work is as low as $5.4 \mathrm{MPa}$. Nevertheless, the NP Cu@Zr-Cu-Al MG composite and NP Zr-Cu-Al MG displayed good bendability without fracture at large bending degree (i.e., $\sim 180^{\circ}$ ), but the NP $\mathrm{Cu}$ was fragile and easily fragmented under bending force, as shown in the insets of Fig. 5a. The crack defects fundamentally determine the macroscopic fragility of NPMs because the cracked NPMs sample is easily crushed since the cracks nucleate from the inherent micro-cracks and quickly propagate along with the concentrated stress [21]. There was no crack defect in the NP Cu@Zr-Cu-Al MG composite (Fig. $4 \mathrm{~b}$ ), while the NP Cu consisted of many large micro-cracks (Fig. S5a). The micro-cracks should have arisen from the hierarchical structure of $\mathrm{NP} \mathrm{Cu}$ [38]; the outer NP Cu layer could be easily separated and shed from the inner NP Cu layer, and then the crack defect would have formed. Therefore, the excellent flexibility of NP Cu@Zr-Cu-Al MG arises from their non-cracking structure, and the existence of flexible $\mathrm{Zr}-\mathrm{Cu}-\mathrm{Al}$ MG. Fig. $5 \mathrm{~b}$ and $\mathrm{c}$ show the nanoindentation curves and the corresponding nanomechanical properties of the NP Zr$\mathrm{Cu}-\mathrm{Al}$ MG, NP Cu and NP Cu@Zr-Cu-Al MG composite. Fig. 5c shows that the $H$ of NP Cu@Zr-Cu-Al MG is $0.79 \mathrm{GPa}$, much higher than that of $\mathrm{NP} \mathrm{Cu}(H=$ $0.018 \mathrm{GPa}$ ). The corresponding SPM images and 3D plots, as well as the linear sweep and roughness measurements after nanoindentation, are shown in Fig. 5d-g. Both the NP Zr-Cu-Al MG and NP Cu@Zr-Cu-Al MG composite (Fig. 5d, e and g) generated excellent nanoindentation morphology with a smooth profile without the formation of microcracks, indicating good mechanical integrity under external nanoindentation force. On the other hand, the NP Cu (Fig. $5 f$ and g) contains the prominent cracked parts on the rough profile of the sample surface. This result is related to the poor nanoindentation properties for $\mathrm{NP} \mathrm{Cu}$ (Fig. 5c). Moreover, the nanohardness value of NP Cu@Zr-Cu-Al MG was approximately three times greater than that of other reported nanoporous pure metals $[21,35,36]$. The results are summarized in Table 1 . The highly strong interior $\mathrm{Zr}-\mathrm{Cu}-$ Al MG acted as a strengthening phase for absorbing much deformation energy and subsequently delaying the failure of nanoporous ligaments [38].

The superior mechanical performance of NP-Cu@Zr$\mathrm{Cu}-\mathrm{Al} \mathrm{MG}$ composite can be further explained using the G-A equation [21-23]. Fig. 6 shows the curves of the strength versus relative density for the NP Cu@Zr-Cu-Al MG composite, NP Zr-Cu-Al MG, NP Cu, other reported nanoporous pure metals (NP Au [15,20,41-44], NP Ag $[17,21,45], \mathrm{NP} \mathrm{Cu}[46]$, and NP Ni [35]), and NP MG (NP Mg-Al MG [47] and NP Ni-Pd-P-B MG [48]). The strength and nanohardness of the NPMs were correlated by $\sigma=H / 2.65(P<70 \%)$ and $\sigma=H(P>70 \%)$ [35]. In the present case, the G-A equation is defined as follows:

$$
\begin{aligned}
& \sigma_{\text {nanoporous }}=0.3 \sigma_{\text {solid }} \phi^{3 / 2}, \\
& H_{\text {nanoporous }}=C H_{\text {solid }} \phi^{3 / 2},
\end{aligned}
$$

where $\sigma_{\text {solid }}$ and $H_{\text {solid }}$ are the strength and hardness of the solid phase (nano-ligaments in NPMs), respectively. $C$ is a constant having an approximate value of 0.47 , and $\varphi$ is the relative density of porous materials and can be calculated as $\varphi=1-P$ [17], where $P$ denotes the porosity obtained from the BET measurements. The G-A lines of the NP $\mathrm{Zr}-\mathrm{Cu}-\mathrm{Al} \mathrm{MG}$ were estimated based on the $\mathrm{Zr}$ $\mathrm{Cu}-\mathrm{Al} \mathrm{MG}$ ligaments with the theoretical $\sigma_{\text {solid }}$ of $2000 \mathrm{MPa}[29,30]$ and $H_{\text {solid }}$ of $6.75 \mathrm{GPa}$. Moreover, the $\mathrm{G}-\mathrm{A}$ lines of the NP $\mathrm{Cu}$ were estimated based on the $\mathrm{Cu}$ ligaments with the $\sigma_{\text {solid }}$ of $400 \mathrm{MPa}$ [49], and $H_{\text {solid }}$ of $1.32 \mathrm{GPa}$. The $H_{\text {solid }}$ of $\mathrm{Zr}-\mathrm{Cu}-\mathrm{Al} \mathrm{MG}$ ligaments and $\mathrm{Cu}$ 

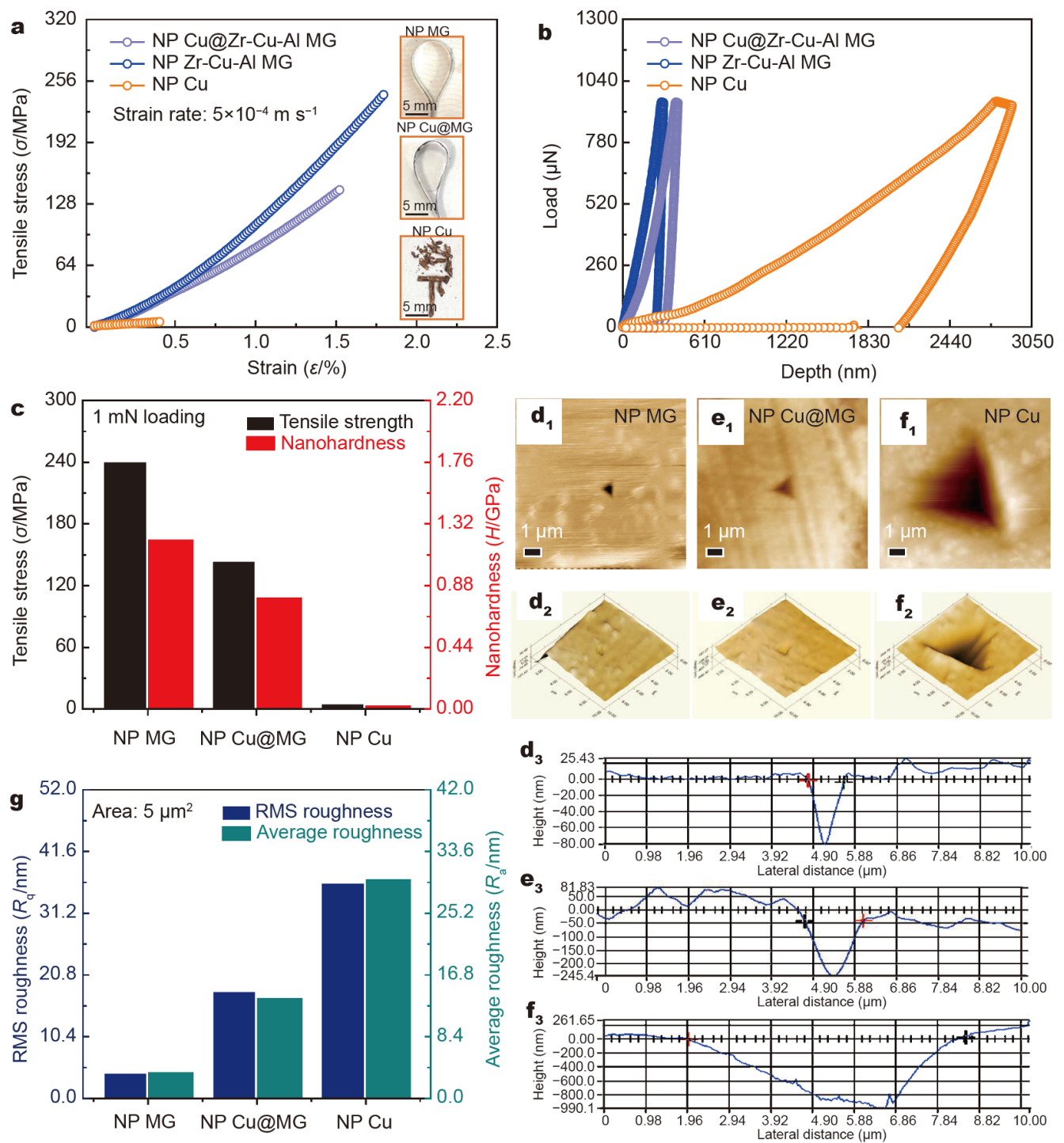

Figure 5 Mechanical measurements of the NP Cu@Zr-Cu-Al MG hybrid alloy. (a) Tensile stress-strain curves. (b) Nanoindentation force-depth curves. (c) Comparison of mechanical properties of the NP Cu@Zr-Cu-Al MG hybrid alloy with NP Zr-Cu-Al MG alloy and NP Cu metal. (d-g) The SPM images, 3D plots, and the linear sweep and roughness measurements of the NP Cu@Zr-Cu-Al MG, NP Zr-Cu-Al MG and NP Cu samples after nanoindentation.

ligaments were extracted by measuring the $H_{\text {solid }}$ of pure $\mathrm{Zr}-\mathrm{Cu}-\mathrm{Al}$ glassy alloy and pure $\mathrm{Cu}$, as shown in Fig. S6. The G-A lines for NP $\mathrm{Zr}-\mathrm{Cu}-\mathrm{Al} \mathrm{MG}$ and $\mathrm{NP} \mathrm{Cu}$ are the upper and lower boundaries of the Cu@Zr-Cu-Al MG composite, respectively. The strength of the NP Cu@Zr$\mathrm{Cu}-\mathrm{Al}$ MG composite is close to the upper G-A lines, while the NP $\mathrm{Cu}$ and other reported nanoporous pure metals are located in the lower G-A line region (Fig. 6). The NPCu@Zr-Cu-Al MG composite exhibited excellent flexibility, strength, and hardness due to the introduction of the high-strength $\mathrm{Zr}-\mathrm{Cu}-\mathrm{Al} \mathrm{MG}$ into the $\mathrm{NP} \mathrm{Cu}$.

The failure of NPMs arose due to the initiation and propagation of micro-cracks, which finally penetrated the entire material. The metal with 3D nanoporous structure cracks more easily than its bulk counterparts owing to its irregular open-cell structures $[12,13]$. The distributions of the size, shape, and surface curvature of the ligaments in NPMs were irregular. Hence, when the NPMs were subjected to an external loading force, the weakest ligaments would be preferentially ruptured, and then the cracks would form [12,14]. Subsequently, the ligaments failed one-by-one, and consequently, the cracks grew continuously along the direction normal to the applied loading force. Finally, the NPMs were fractured when the 


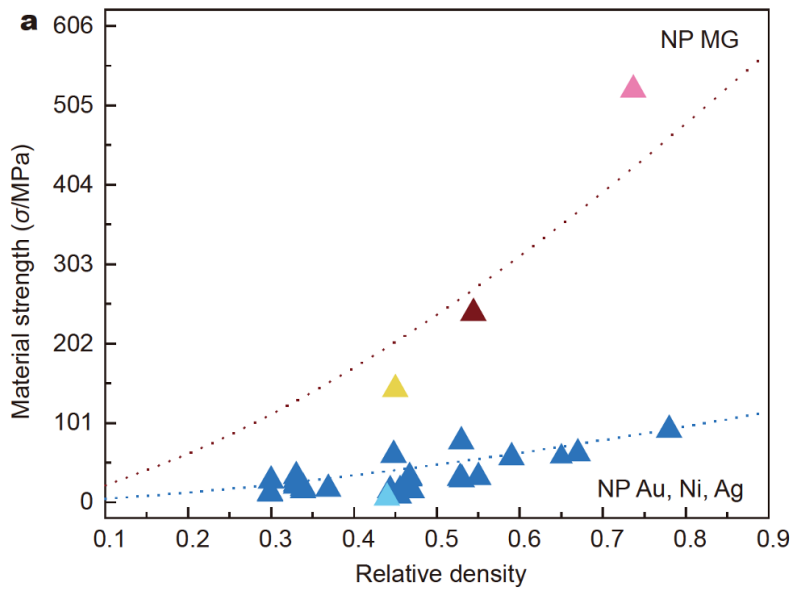

Previous literatures

A Tension (NP Au [15,20,42,44], NP Ni [35], NP Ag [17,21])

$\triangle$ Tension (NP Mg-Al MG [47])

This work

- NP Zr-Cu-Al MG/Tension

A NPCu@Zr-Cu-Al MG/Tension

- NP Cu/Tension

Gibson-Ashby model for

- - - Zr-Cu-AI MG: $\sigma_{\text {solid }}=2000$ MPa $[29,30]$

-..--Pure Cu: $\sigma_{\text {solid }}=400 \mathrm{MPa}$ [49]

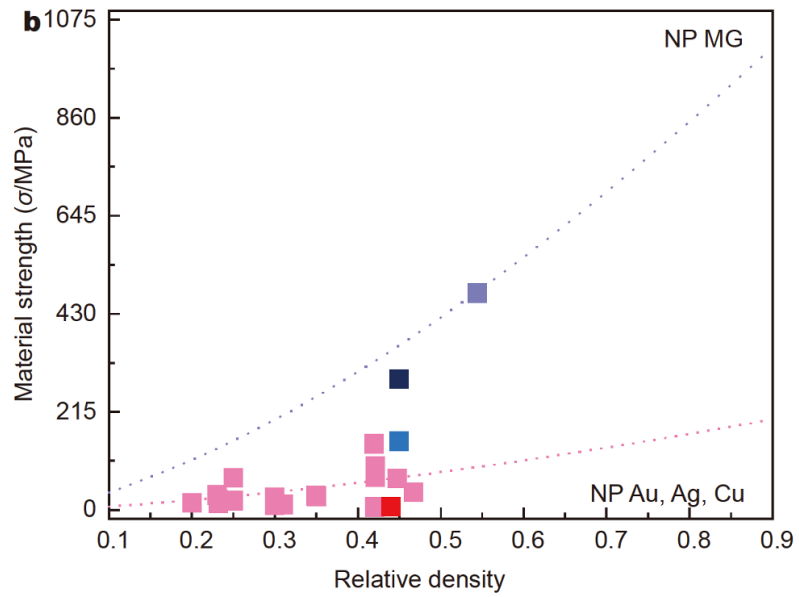

Previous literatures

- Nanoindentation (NP Au [41-43], NP Ag [21,45], NP Cu [46])

- Nanoindentation (NP Ni-Pd-P-B MG [48])

This work

- NP Zr-Cu-Al MG/Nanoindentation

- NPCu@Zr-Cu-Al MG/Nanoindentation

- NP Cu/Nanoindentation Gibson-Ashby model for -..- Zr-Cu-AI MG: $H_{\text {solid }}=6.75 \mathrm{GPa}$ [In this work] Pure Cu: $H_{\text {solid }}=1.32 \mathrm{GPa}$ [In this work]

Figure 6 (a, b) Mechanical properties of nanoporous metals. Blue and black lines denote upper and lower boundaries estimated using G-A model (Equations (2) and (3)) for NP Cu@Zr-Cu-Al MG hybrid alloy, respectively.

Table 1 Comparison of the nanoporous metal materials in terms of mechanical properties

\begin{tabular}{cccccc}
\hline Sample & Relative density (\%) & Ligament size $(\mathrm{d} / \mathrm{nm})$ & $\begin{array}{c}\text { Ultimate strength } \\
(\sigma / \mathrm{MPa})\end{array}$ & $\begin{array}{c}\text { Nanohardness } \\
(\mathrm{H} / \mathrm{GPa})\end{array}$ & Reference \\
\hline NP Zr-Cu-Al MG & 53 & 25 & 240.7 & 1.27 & This work \\
NP Cu@Zr-Cu-Al MG & 45 & 19 & 143.9 & 0.79 & This work \\
NP Cu & 44 & 35 & 5.4 & 0.018 & This work \\
NP Ag & 41 & 127 & 27.5 & 0.21 & {$[21]$} \\
NP Au & 35 & 43 & 30 & 0.24 & {$[23]$} \\
NP Ni & 46 & 350 & 25 & 0.24 & {$[35]$} \\
NP Cu & 39 & 43 & & & {$[36]$} \\
\hline
\end{tabular}

cracks propagated through the entire material. If the ligaments are strong enough to sustain loading without breaking down, the initiation and development of microcracks are suppressed, and the fracture of NPMs is delayed.

The NPCu@Zr-Cu-Al MG composite showed much higher intrinsic strength and hardness than NP Cu due to the $\mathrm{Zr}-\mathrm{Cu}-\mathrm{Al} \mathrm{MG}$ reinforced phase in the ligaments (Fig. 5). Because of the uniform amorphous and isotropic structure [29,30], MG alloys have no crystal defects traditionally found in crystalline metals, such as the grain boundaries, stacking faults, and dislocations. As a result, the typical intergranular and transgranular fractures found in crystalline metals would not occur in MG alloys. 
Moreover, insufficient toughness of non-uniform crystal structure, which leads to the premature fracture in metallic materials, does not occur in MG alloys $[29,30]$. The $\mathrm{Zr}-\mathrm{Cu}-\mathrm{Al}$ MG phase for the NP Cu@Zr-Cu-Al MG composite plays a strengthening role for depressing the rupture of individual $\mathrm{Cu@Zr-Cu-Al} \mathrm{ligament,} \mathrm{which}$ could effectively restrain the crack initiation and propagation in the NPMs (Fig. 7a and b), and finally improve the comprehensive mechanical properties.

The NPCu@Zr-Cu-Al MG and NP Cu were subjected to the high loading force of $0.1 \mathrm{~N}$ using the Vickers hardness indentation to verify if NP Cu@Zr-Cu-Al MG could effectively restrain the formation and development of cracks. As shown in Fig. 7c and d, Vickers hardness of the NPCu@Zr-Cu-Al MG is approximately 148.5, which is much higher than that of the NP Cu. Furthermore, it is easily observed that the single large microcrack $(>40 \mu \mathrm{m})$ penetrates the entire indentation traces in $\mathrm{NP} \mathrm{Cu}$ along the edges (Fig. 7c). On the contrary, the multiple small cracks $(<1 \mu \mathrm{m})$ are well dispersed around the indentation trace region of NP Cu@Zr-Cu-Al MG; these multiple small cracks do not assemble along the indenter edges where the stress is concentrated, indicating its good ability to resist crack initiation and propagation (Fig. 7d). Therefore, the NP Cu@Zr-Cu-Al MG demonstrated the excellent flexibility, strength, and hardness (Figs 5-7). However, the NP $\mathrm{Cu}$ displayed the macroscopic fragility and superior low strength and hardness (Figs 5-7).

\section{Electrochemical performance of the NP Cu@Zr-Cu-Al MG composite}

The supercapacitor and glucose biosensor properties of the NP Cu@Zr-Cu-Al MG composite were determined by electrochemical tests in $0.2 \mathrm{~mol} \mathrm{~L}^{-1} \mathrm{NaOH}$ solution. Fig. 8a shows the CV curves of the NP Cu@Zr-Cu-Al MG composite, $\mathrm{NP} \mathrm{Zr}-\mathrm{Cu}-\mathrm{Al} \mathrm{MG}$ and $\mathrm{NP} \mathrm{Cu}$ at a scan rate of $25 \mathrm{mV} \mathrm{s}^{-1}$. All CV curves contain the prominent redox peaks. The capacitance behavior is primarily based on the Faradaic redox reactions, which occurs due to the adsorption of electrolyte ions onto the surface of electroactive materials during the reversible reactions [50]. CV curve of the NP Zr-Cu-Al MG (Fig. 8a) shows one pair of the redox peaks $\left(\mathrm{A}_{2} / \mathrm{C}_{2}\right)$; however, $\mathrm{CV}$ curves of the NP $\mathrm{Cu} @ \mathrm{Zr}-\mathrm{Cu}-\mathrm{Al} \mathrm{MG}$ composite and NP Cu show two pairs of redox peaks $\left(A_{1} / C_{1}, A_{2} / C_{2}\right)$, which agree with the results reported in the literature [51,52]. The oxido-reduction processes are described as following [51,52]:

Oxido-reduction peaks $\left(\mathrm{A}_{1} / \mathrm{C}_{1}\right)$ :

$\mathrm{Cu}(0)+\mathrm{OH}^{-} \rightarrow \mathrm{CuOH}+\mathrm{e}^{-}$,

$2 \mathrm{CuOH} \rightarrow \mathrm{Cu}_{2} \mathrm{O}+\mathrm{H}_{2} \mathrm{O}$.

Oxido-reduction peaks $\left(\mathrm{A}_{2} / \mathrm{C}_{2}\right)$ :

$\mathrm{Cu}(0)+2 \mathrm{OH}^{-} \rightarrow \mathrm{Cu}(\mathrm{OH})_{2}+2 \mathrm{e}^{-}$,

$\mathrm{Cu}_{2} \mathrm{O}+2 \mathrm{OH}^{-}+\mathrm{H}_{2} \mathrm{O} \rightarrow 2 \mathrm{Cu}(\mathrm{OH})_{2}+2 \mathrm{e}^{-}$,

$\mathrm{Cu}(\mathrm{OH})_{2} \rightarrow \mathrm{CuO}+\mathrm{H}_{2} \mathrm{O}$.

The NP Cu@Zr-Cu-Al MG composite and NP Cu
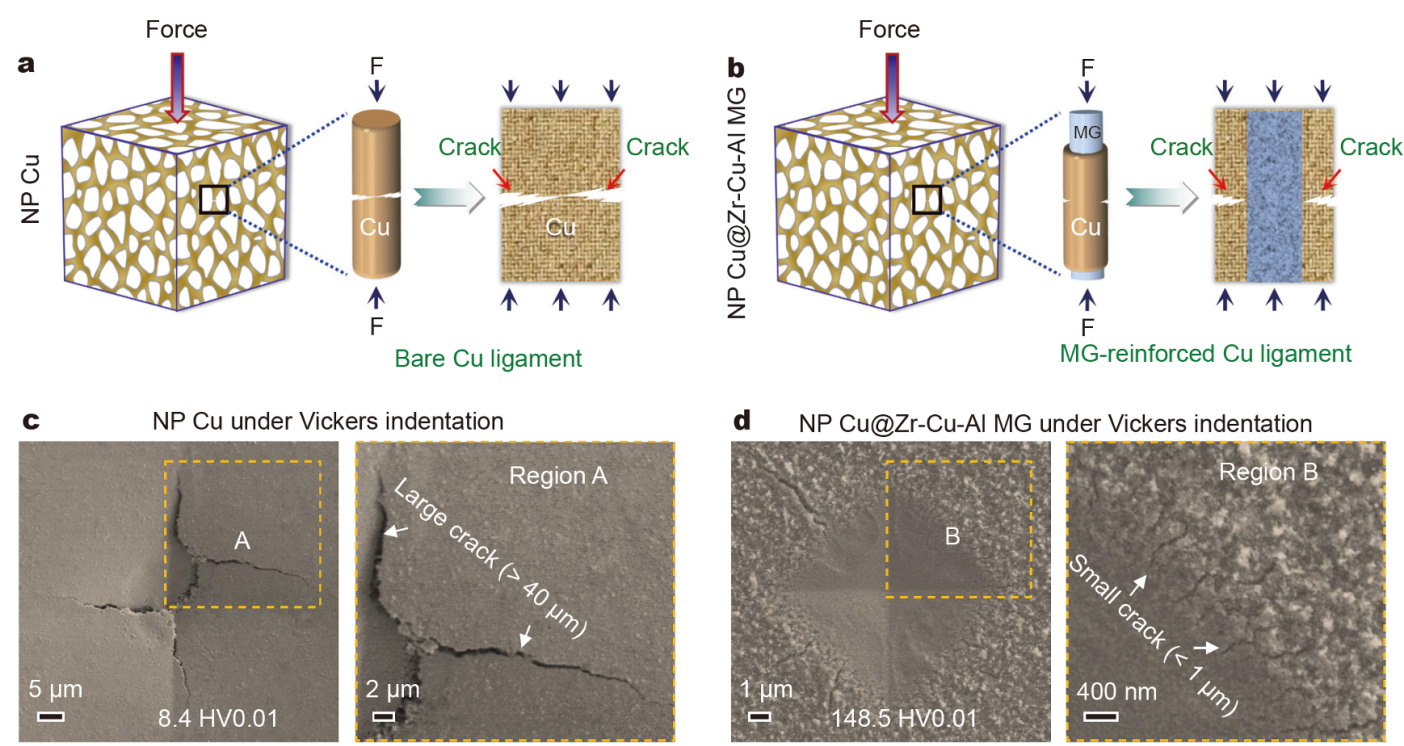

Figure 7 (a, b) Schematic illustration showing the strengthening mechanism of the NP Cu@Zr-Cu-Al MG composite than the bare NP Cu metal. (c, d) SEM images showing the surface morphologies of bare NP Cu samples and NP Cu@Zr-Cu-Al MG composite samples after high-load Vickers hardness indentations. 

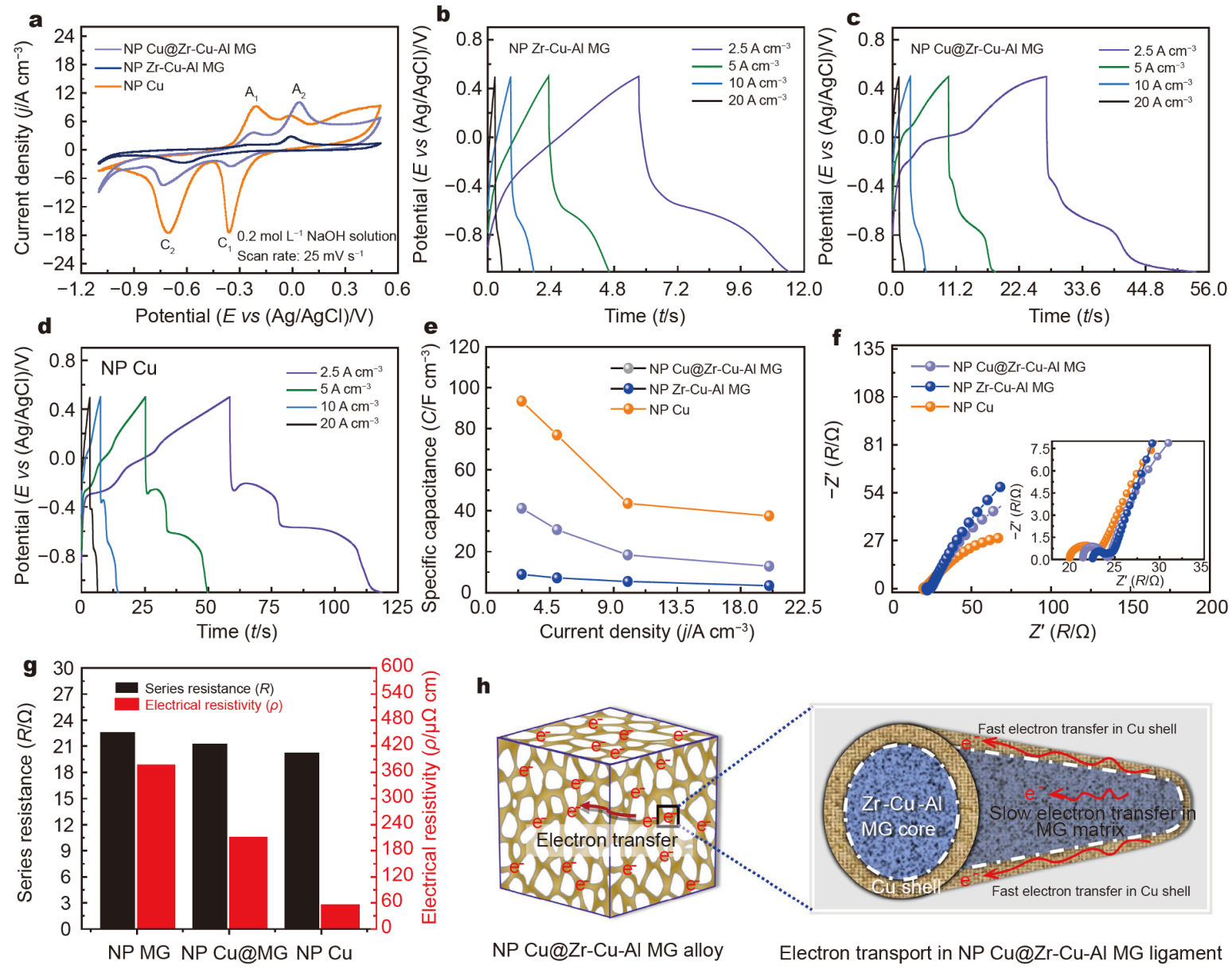

NP Cu@Zr-Cu-Al MG alloy_ Electron transport in NP Cu@Zr-Cu-Al MG ligament

Figure 8 Electrochemical capacitive properties. (a) CV curves. (b-d) GCD curves of the three electrodes at different current densities. (e) Volumetric specific capacitances of the three electrodes under various conditions. (f, g) EIS analyses and electrical conductivity. (h) Schematic illustration showing the benefits of the NPCu@Zr-Cu-Al MG hybrid electrode for high conductive properties.

showed remarkably enhanced capacitive current than the bare NP Zr-Cu-Al MG (Fig. 8a). Fig. 8b-d show the GCD curves of the NP Cu@Zr-Cu-Al MG composite, NP Zr$\mathrm{Cu}-\mathrm{Al} \mathrm{MG}$, and $\mathrm{NP} \mathrm{Cu}$ at various current densities. The volumetric specific capacitance values $\left(C_{\mathrm{v}}, \mathrm{F} \mathrm{cm}^{-3}\right)$ of the NP Cu@Zr-Cu-Al MG composite, NP Cu, and NP Zr$\mathrm{Cu}-\mathrm{Al} \mathrm{MG}$ are calculated from the $\mathrm{CV}$ and GCD curves using the following formula [53]:

$C=\frac{I \Delta t}{V_{\mathrm{sc}} \Delta E}$,

where $I$ is the discharge current $(\mathrm{A})$, and $\Delta t$ is the discharge time (s), $\Delta E=E_{2}-E_{1}$ is the operation voltage region with $E_{1}=0.5 \mathrm{~V}$ and $E_{2}=-1.1 \mathrm{~V}$, and $V_{\mathrm{sc}}$ is the total volume of the as-prepared electrodes $\left(\mathrm{cm}^{3}\right)$. The NP $\mathrm{Cu} @ \mathrm{Zr}-\mathrm{Cu}-\mathrm{Al}$ hybrid electrodes and the NP Cu electrodes obtained higher capacitances than the NP $\mathrm{Zr}-\mathrm{Cu}-\mathrm{Al}$ MG electrodes (Fig. 8e). The poor capacitive behavior of the NP Zr-Cu-Al MG electrode possibly originated from the poor electrical conductivity of MG alloys [31]. Moreover, plenty of the $\mathrm{Zr}$ and $\mathrm{Al}$ elements in $\mathrm{NP} \mathrm{Zr}-\mathrm{Cu}-$ Al MG damaged its electrochemical behavior owing to their poor chemical activities. On the contrary, the $\mathrm{Cu}$ based crystalline alloys exhibited high conductivity [54]. Therefore, the NPCu@Zr-Cu-Al MG composite demonstrated better energy storage performance than the bare NP $\mathrm{Zr}-\mathrm{Cu}-\mathrm{Al} \mathrm{MG}$.

The electrical conductivities of the NPCu@Zr-Cu-Al MG composite, NP $\mathrm{Cu}$, and NP $\mathrm{Zr}-\mathrm{Cu}-\mathrm{Al}$ MG were investigated by EIS tests and a conventional four-probe method [31]. Fig. 8f reveals the Nyquist plots of the three samples. The intercept of the Nyquist plots on the real axis represents the value of an equivalent series resistance $(R)$, which is related to the electrolyte resistance, the intrinsic resistance of electrode material, and the contact 
resistance at the interface between the active material and substrate [55]. The NP Cu@Zr-Cu-Al MG composite and NP $\mathrm{Cu}$ showed lower $R$ than the NP $\mathrm{Zr}-\mathrm{Cu}-\mathrm{Al}$ MG. Moreover, the electrical resistivity $(\rho)$ of $\mathrm{NP} \mathrm{Cu}$ was $54.18 \mu \Omega \mathrm{cm}$, which is 5.9 times lower than that of the NP $\mathrm{Zr}$-Cu-Al MG $(\rho=376.23 \mu \Omega \mathrm{cm})$ (Fig. 8g). Therefore, the good conductivity of the NP Cu@Zr-Cu-Al MG composite is attributed to the good conductivity of pure $\mathrm{Cu}$ layer on the $\mathrm{Zr}-\mathrm{Cu}$ - $\mathrm{Al}$ MG ligament, as schematically shown in Fig. 8h. The excellent conductivity of materials can enhance the electrode/electrolyte interfacial contact and promote electronic/ion conductivity to accelerate the Faradaic reactions [56,57]. Hence, the NP Cu@Zr-Cu-Al MG composite has a better capacitive performance than the bare NP Zr-Cu-Al MG (Fig. 8e).

The electrocatalytic activities of the flexible NPCu@Zr$\mathrm{Cu}-\mathrm{Al} \mathrm{MG}$ composite towards glucose oxidation were examined to evaluate their potential application in glucose electrochemical sensing. Fig. S7a illustrates the CV curves of the NP Cu@Zr-Cu-Al MG composite in $0.2 \mathrm{~mol} \mathrm{~L}^{-1} \mathrm{NaOH}$ solution with and without $5 \mathrm{mmol} \mathrm{L}^{-1}$ glucose at a scan rate of $25 \mathrm{mV} \mathrm{s}^{-1}$. Moreover, the anodic oxidation current in $\mathrm{NaOH}$ solution with glucose is much higher than in $\mathrm{NaOH}$ solution without glucose; it indicates that the NPCu@Zr-Cu-Al MG composite displays glucose sensing performance (Fig. S7a). The increment in current at the first stage $(<0 \mathrm{~V})$ is possibly due to the electro-adsorption of glucose and generation of adsorbed intermediates (one proton is lost per-glucose molecule in this electrochemical reaction) [58]. In the second stage $(>0 \mathrm{~V})$, current increment is observed possibly due to the direct oxidation of glucose, resulting in much-transferred charge [58]. Fig. S7b shows the CV curves of the NP $\mathrm{Cu} \mathrm{Zr}-\mathrm{Cu}-\mathrm{Al}$ MG composite with various scan rates in a $0.2 \mathrm{~mol} \mathrm{~L}^{-1} \mathrm{NaOH}$ solution containing $5 \mathrm{mmol} \mathrm{L}^{-1}$ glucose electrolyte. As shown in Fig. S7c, the two anodic peak currents are found to be linearly associated with the square root of the scan rate; it shows a typical diffusioncontrolled electrochemical process, which is useful for quantitative analysis of real detections [59]. Therefore, the NPCu@Zr-Cu-Al MG composite material is suitable for practical biosensor applications in quantitative analysis of glucose. Moreover, Li et al. [52] have reported that for the NP Cu there exists a direct relation between $1 / R_{\mathrm{ct}}$ and its glucose concentration; here, $R_{\mathrm{ct}}$ is the charge transfer resistance, $1 / R_{\mathrm{ct}}=K C_{\text {glucose }}$ with $K$ being a constant parameter. The inverse of charge transfer resistance, $1 / R_{\mathrm{ct}}$, is linearly dependent on the glucose concentration in the range of 1 to $10 \mathrm{mmol} \mathrm{L}^{-1}$ with a regression coefficient of 0.992. Therefore, the concentrations of glucose can be quantitatively detected with the NP Cu@Zr-Cu-Al MG by EIS method. Nevertheless, the NP Cu@Zr-Cu-Al MG electrode may not selectively detect the glucose; it is because the nanoporous transition $\mathrm{Cu}, \mathrm{AuCu}$, and $\mathrm{AuAg}$ metals demonstrated highly sensitive detection towards various biological substances, such as glucose, dopamine and uric acid [52,58,60]. Radhakrishnan et al. [61] reported that $\mathrm{CuS}$ electrode could selectively detect the glucose from the ascorbic acid (AA), uric acid (UA), dopamine (DA), and fructose (Fru). Therefore, an appropriate sulfuration of NP Cu@Zr-Cu-Al MG to form an amount of CuS should improve the selectivity of the glucose biosensor. In our future work, the research focus will be on the detailed research to achieve the desirable selectivity, good quantitative detectability, and low detection limit of glucose biosensors.

To further investigate the potential of the NP Cu@Zr$\mathrm{Cu}-\mathrm{Al} \mathrm{MG}$ composite as a flexible free-standing glucose biosensor electrode, the $\mathrm{CV}$ tests on the sample subjected to bending under a large angle $\left(\sim 120^{\circ}\right)$ were performed (Fig. S7d). Both normal and bending NP Cu@Zr-Cu-Al MG composites display a similar electrochemical performance, indicating the excellent electrochemical stability during bending. The mechanical stability of the flexible NPCu@Zr-Cu-Al MG composite after CV tests in the glucose was examined by nanoindentation and Vickers hardness. The NP Cu@Zr-Cu-Al MG composite still retains the high nanohardness $(H=0.74 \mathrm{GPa})$ and Vickers hardness (118.1 HV0.01), and shows good indentation morphology, indicating superior mechanical stability after the electrochemical testing (Fig. S8). The $\mathrm{NP} \mathrm{Cu} @ \mathrm{Zr}-\mathrm{Cu}-\mathrm{Al}$ MG composite displays good comprehensive properties, such as electrochemical properties, flexibility, and mechanical properties (Figs $5-7$ and Table 1). These characteristics are promising for their practical applications in flexible supercapacitors and glucose biosensors, especially as the power source units for bendable electronics and the sensory units for wearable healthcare monitoring devices, such as the roll-up displays, smart watches, portable screens, artificial electronic skins, and implantable medical biosensors.

\section{CONCLUSIONS}

The highly strong and flexible NP Cu@Zr-Cu-Al MG composite ribbons were successfully fabricated by dealloying the NP Zr-Cu-Al MG ribbon. The NP Cu@Zr-CuAl MG demonstrated a large tensile strength $(\sigma)$ of 143.9 $\mathrm{MPa}$, nanohardness $(H)$ of $0.79 \mathrm{GPa}$, and Vickers hardness (HV0.01) of 148.5; these values are much higher than those of pure NP Cu $(\sigma=5.4 \mathrm{MPa}, H=0.018 \mathrm{GPa}$, 
HV0.01 = 8.4). The $\mathrm{Zr}-\mathrm{Cu}-\mathrm{Al}$ MG phase played a strengthening role in depressing the rupture of individual $\mathrm{Cu} @ \mathrm{Zr}$ - $\mathrm{Cu}$-Al ligament, which effectively restrained the crack initiation and propagation. Finally, it improved the comprehensive mechanical properties. The outstanding comprehensive mechanical properties of the flexible NP $\mathrm{Cu} \mathrm{Zr}-\mathrm{Cu}-\mathrm{Al}$ MG originated from their non-cracking structure and the existence of flexible $\mathrm{Zr}-\mathrm{Cu}-\mathrm{Al} \mathrm{MG}$. Additionally, the flexible NP Cu@Zr-Cu-Al MG composite ribbon can be directly used as a free-standing electrode for supercapacitors and glucose biosensors. The NP $\mathrm{Cu} \mathrm{Zr}-\mathrm{Cu}-\mathrm{Al}$ MG composite showed better electrical conductivity than NP Zr-Cu-Al MG owing to the existence of continuous $\mathrm{Cu}$ on the surface of ligaments. The as-prepared flexible NP Cu@Zr-Cu-Al MG materials with the good physicochemical properties are promising candidates for the application in micro-electromechanical systems, such as wearable healthcare and flexible electronic devices.

Received 21 September 2020; accepted 6 January 2021; published online 12 March 2021

1 Kim J, Campbell AS, de Ávila BEF, et al. Wearable biosensors for healthcare monitoring. Nat Biotechnol, 2019, 37: 389-406

2 Park S, Heo SW, Lee W, et al. Self-powered ultra-flexible electronics via nano-grating-patterned organic photovoltaics. Nature, 2018, 561: 516-521

3 Pomerantseva E, Bonaccorso F, Feng X, et al. Energy storage: The future enabled by nanomaterials. Science, 2019, 366: eaan8285

4 Zhu Y, Yang M, Huang Q, et al. $\mathrm{V}_{2} \mathrm{O}_{5}$ textile cathodes with high capacity and stability for flexible lithium-ion batteries. Adv Mater, 2020, 32: 1906205

5 Xie JQ, Ji YQ, Kang JH, et al. In situ growth of $\mathrm{Cu}(\mathrm{OH})_{2} @ \mathrm{FeOOH}$ nanotube arrays on catalytically deposited $\mathrm{Cu}$ current collector patterns for high-performance flexible in-plane micro-sized energy storage devices. Energy Environ Sci, 2019, 12: 194-205

6 Liu X, Zhang R, Yu W, et al. Three-dimensional electrode with conductive $\mathrm{Cu}$ framework for stable and fast Li-ion storage. Energy Storage Mater, 2018, 11: 83-90

7 Ge W, Encinas A, Ruiz MF, et al. Facile fabrication of nanoporous nickel with rational pore structure decorated with ultrathin $\mathrm{Ni}(\mathrm{OH})_{2}$ nanosheets as advanced supercapacitor electrodes. Scripta Mater, 2020, 178: 155-160

8 Shi L, Rong X, Wang Y, et al. High-performance and versatile electrochemical aptasensor based on self-supported nanoporous gold microelectrode and enzyme-induced signal amplification. Biosens Bioelectron, 2018, 102: 41-48

9 Li R, Liu XJ, Wang H, et al. Formation mechanism and characterization of nanoporous silver with tunable porosity and promising capacitive performance by chemical dealloying of glassy precursor. Acta Mater, 2016, 105: 367-377

10 Baghayeri M, Veisi H. Fabrication of a facile electrochemical biosensor for hydrogen peroxide using efficient catalysis of hemoglobin on the porous $\mathrm{Pd} @ \mathrm{Fe}_{3} \mathrm{O}_{4}$-MWCNT nanocomposite. Biosens Bioelectron, 2015, 74: 190-198
11 Wang X, Shang L, Zhang W, et al. An ultrasensitive luminol cathodic electrochemiluminescence probe with highly porous $\mathrm{Pt}$ on ionic liquid functionalized graphene film as platform for carcinoembryonic antigen sensing. Biosens Bioelectron, 2019, 141: 111436

12 Biener J, Hodge AM, Hamza AV. Microscopic failure behavior of nanoporous gold. Appl Phys Lett, 2005, 87: 121908

13 Li R, Sieradzki K. Ductile-brittle transition in random porous Au. Phys Rev Lett, 1992, 68: 1168-1171

14 Liu P, Wei X, Song S, et al. Time-resolved atomic-scale observations of deformation and fracture of nanoporous gold under tension. Acta Mater, 2019, 165: 99-108

15 Badwe N, Chen X, Sieradzki K. Mechanical properties of nanoporous gold in tension. Acta Mater, 2017, 129: 251-258

16 Chen F, Chen X, Zou L, et al. Fabrication and mechanical behavior of bulk nanoporous $\mathrm{Cu}$ via chemical de-alloying of $\mathrm{Cu}-\mathrm{Al}$ alloys. Mater Sci Eng-A, 2016, 660: 241-250

17 Zabihzadeh S, Van Petegem S, Holler M, et al. Deformation behavior of nanoporous polycrystalline silver. Part I: Microstructure and mechanical properties. Acta Mater, 2017, 131: 467-474

18 Kim YC, Gwak EJ, Ahn S, et al. Indentation size effect in nanoporous gold. Acta Mater, 2017, 138: 52-60

19 Leitner A, Maier-Kiener V, Jeong J, et al. Interface dominated mechanical properties of ultra-fine grained and nanoporous $\mathrm{Au}$ at elevated temperatures. Acta Mater, 2016, 121: 104-116

20 Gwak EJ, Jeon H, Song E, et al. Twinned nanoporous gold with enhanced tensile strength. Acta Mater, 2018, 155: 253-261

21 Wang C, Zhu S, Liang Y, et al. Understanding the macroscopical flexibility/fragility of nanoporous Ag: Depending on network connectivity and micro-defects. J Mater Sci Tech, 2020, 53: 91-101

22 Gibson LJ, Ashby MF. Cellular Solids: Structure and Properties. Cambridge: Cambridge University, 1997

23 Liu LZ, Ye XL, Jin HJ. Interpreting anomalous low-strength and low-stiffness of nanoporous gold: Quantification of network connectivity. Acta Mater, 2016, 118: 77-87

$24 \mathrm{Hu}$ J, Shi YN, Sauvage X, et al. Grain boundary stability governs hardening and softening in extremely fine nanograined metals. Science, 2017, 355: 1292-1296

25 Lu K. Stabilizing nanostructures in metals using grain and twin boundary architectures. Nat Rev Mater, 2016, 1: 16019

$26 \mathrm{Lu} \mathrm{K}, \mathrm{Lu} \mathrm{L}$, Suresh S. Strengthening materials by engineering coherent internal boundaries at the nanoscale. Science, 2009, 324: 349-352

27 Jiao W, Liu P, Lin $\mathrm{H}$, et al. Tunable nanoporous metallic glasses fabricated by selective phase dissolution and passivation for ultrafast hydrogen uptake. Chem Mater, 2017, 29: 4478-4483

28 Jin $\mathrm{Y}, \mathrm{Li} \mathrm{R}, \mathrm{Xu} \mathrm{H}$, et al. A new strategy to fabricate nanoporous iron-based metallic glasses: Selective phase tailoring of amorphousnanocrystalline composite alloys through electrochemical dissolution. Scripta Mater, 2017, 133: 14-18

29 Inoue A, Takeuchi A. Recent development and application products of bulk glassy alloys. Acta Mater, 2011, 59: 2243-2267

30 Inoue A. Stabilization of metallic supercooled liquid and bulk amorphous alloys. Acta Mater, 2000, 48: 279-306

31 Umetsu RY, Tu R, Goto T. Thermal and electrical transport properties of Zr-based bulk metallic glassy alloys with high glassforming ability. Mater Trans, 2012, 53: 1721-1725

32 Park ES, Kim DH. Phase separation and enhancement of plasticity in $\mathrm{Cu}-\mathrm{Zr}-\mathrm{Al}-\mathrm{Y}$ bulk metallic glasses. Acta Mater, 2006, 54: 25972604 
33 Qin CL, Wang ZF, Liu H, et al. Monolithic nanoporous copper with novel electrochemical properties fabricated by dealloying $\mathrm{Cu}-\mathrm{Zr}(-\mathrm{Al})$ metallic glasses. Mater Sci Forum, 2014, 783-786: 1925-1930

$34 \mathrm{Bi} \mathrm{HW}$, Inoue $\mathrm{A}$, Han FF, et al. Novel deformation-induced polymorphic crystallization and softening of Al-based amorphous alloys. Acta Mater, 2018, 147: 90-99

35 Kashani H, Chen M. Flaw-free nanoporous Ni for tensile properties. Acta Mater, 2019, 166: 402-412

36 Nam SJ, Hwang JY, Kim HK, et al. Three-dimensional microstructure evolution and mechanical behavior of nanoporous $\mathrm{Cu}$ foams. Acta Mater, 2016, 113: 170-179

37 Liu R, Gruber J, Bhattacharyya D, et al. Mechanical properties of nanocrystalline nanoporous platinum. Acta Mater, 2016, 103: 624632

38 Qin C, Wang C, Hu Q, et al. Hierarchical nanoporous metal/BMG composite rods with excellent mechanical properties. Intermetallics, 2016, 77: 1-5

39 Li R, Liu X, Wang H, et al. Bendable nanoporous copper thin films with tunable thickness and pore features. Corrosion Sci, 2016, 104: 227-235

40 McCue I, Benn E, Gaskey B, et al. Dealloying and dealloyed materials. Annu Rev Mater Res, 2016, 46: 263-286

41 Biener J, Hodge AM, Hamza AV, et al. Nanoporous Au: A high yield strength material. J Appl Phys, 2005, 97: 024301

42 Briot NJ, Kennerknecht T, Eberl C, et al. Mechanical properties of bulk single crystalline nanoporous gold investigated by millimetrescale tension and compression testing. Philos Mag, 2014, 94: 847866

43 Hodge AM, Biener J, Hayes JR, et al. Scaling equation for yield strength of nanoporous open-cell foams. Acta Mater, 2007, 55: 1343-1349

44 Balk TJ, Eberl C, Sun Y, et al. Tensile and compressive microspecimen testing of bulk nanoporous gold. J Min Met Mat Soc, 2009, 61: 26-31

45 Cheng IC, Hodge AM. Strength scale behavior of nanoporous Ag, Pd and Cu foams. Scripta Mater, 2013, 69: 295-298

46 Liu R, Zheng S, Kevin Baldwin J, et al. Synthesis and mechanical behavior of nanoporous nanotwinned copper. Appl Phys Lett, 2013, 103: 241907

47 Zhou X, Wang L, Chen CQ. Improving ductility of nanoporous metallic glasses. Comput Mater Sci, 2019, 167: 111-117

48 Arora HS, Aditya AV, Mukherjee S. Electromechanical behaviour of nanoporous metallic glass. Philos Mag Lett, 2015, 95: 131-137

49 Zhu CF, Du FP, Jiao QY, et al. Microstructure and strength of pure $\mathrm{Cu}$ with large grains processed by equal channel angular pressing. Mater Des (1980-2015), 2013, 52: 23-29

$50 \mathrm{He} \mathrm{W}$, Wang $\mathrm{C}$, Li $\mathrm{H}$, et al. Ultrathin and porous $\mathrm{Ni}_{3} \mathrm{~S}_{2} / \mathrm{CoNi}_{2} \mathrm{~S}_{4}$ 3D-network structure for superhigh energy density asymmetric supercapacitors. Adv Energy Mater, 2017, 7: 1700983

51 Zhang Y, Su L, Manuzzi D, et al. Ultrasensitive and selective nonenzymatic glucose detection using copper nanowires. Biosens Bioelectron, 2012, 31: 426-432

52 Li X, Huang B, Qiu C, et al. Hierarchical nested-network porous copper fabricated by one-step dealloying for glucose sensing. J Alloys Compd, 2016, 681: 109-114

53 Qin P, Li X, Gao B, et al. Hierarchical TiN nanoparticles-assembled nanopillars for flexible supercapacitors with high volumetric capacitance. Nanoscale, 2018, 10: 8728-8734

54 Anderoglu $\mathrm{O}$, Misra A, Wang $\mathrm{H}$, et al. Epitaxial nanotwinned $\mathrm{Cu}$ films with high strength and high conductivity. Appl Phys Lett, 2008, 93: 083108

55 Yang $\mathrm{P}, \mathrm{Wu} \mathrm{Z}$, Jiang $\mathrm{Y}$, et al. Fractal $\left(\mathrm{Ni}_{x} \mathrm{Co}_{1-x}\right)_{9} \mathrm{Se}_{8}$ nanodendrite arrays with highly exposed (01) surface for wearable, all-solidstate supercapacitor. Adv Energy Mater, 2018, 8: 1801392

56 Kang J, Zhang S, Zhang Z. Three-dimensional binder-free nanoarchitectures for advanced pseudocapacitors. Adv Mater, 2017, 29: 1700515

57 Ramadoss A, Yoon KY, Kwak MJ, et al. Fully flexible, lightweight, high performance all-solid-state supercapacitor based on 3dimensional-graphene/graphite-paper. J Power Sources, 2017, 337: 159-165

58 Li X, Qiu HJ, Wang JQ, et al. Corrosion of ternary $\mathrm{Mn}-\mathrm{Cu}-\mathrm{Au}$ to nanoporous $\mathrm{Au}-\mathrm{Cu}$ with widely tuned $\mathrm{Au} / \mathrm{Cu}$ ratio for electrocatalyst. Corrosion Sci, 2016, 106: 55-60

59 Zhuang Z, Su X, Yuan H, et al. An improved sensitivity nonenzymatic glucose sensor based on a $\mathrm{CuO}$ nanowire modified $\mathrm{Cu}$ electrode. Analyst, 2008, 133: 126-132

60 Hou J, Xu C, Zhao D, et al. Facile fabrication of hierarchical nanoporous AuAg alloy and its highly sensitive detection towards dopamine and uric acid. Sens Actuat B-Chem, 2016, 225: 241-248

61 Radhakrishnan S, Kim HY, Kim BS. A novel CuS microflower superstructure based sensitive and selective nonenzymatic glucose detection. Sens Actuat B-Chem, 2016, 233: 93-99

Acknowledgements This work was financially supported by the National Natural Science Foundation of China (51771131) and the Recruitment Program of Global Experts "1000 Talents Plan" of China (WQ20121200052).

Author contributions Wang $\mathrm{C}$ and Zhu $\mathrm{S}$ designed and engineered the samples; Wang $\mathrm{C}$ and $\mathrm{Li} \mathrm{Z}$ performed the experiments; Liang Y, Cui $\mathrm{Z}, \mathrm{Wu} \mathrm{S}$ and Luo $\mathrm{S}$ performed the data analysis; Wang $\mathrm{C}$ and Zhu $\mathrm{S}$ contributed to the theoretical analysis; Wang $\mathrm{C}$ wrote the paper with support from Zhu S, Qin C and Inoue A. All authors contributed to the general discussion.

Conflict of interest The authors declare that they have no conflict of interest.

Supplementary information Experimental details and supporting data are available in the online version of the paper.

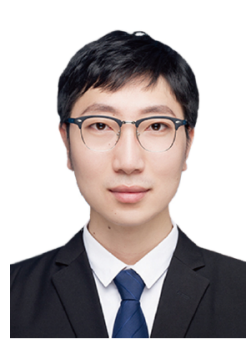

Chaoyang Wang is currently a $\mathrm{PhD}$ student under the supervision of Prof. Akihisa Inoue and Prof. Shengli Zhu at Tianjin University. His current research interests focus on the flexible nanoporous metals, mechanical properties and flexible electronics. 


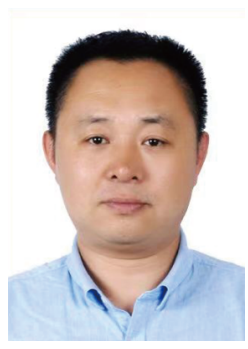

Shengli Zhu is currently a Professor at Tianjin University. He received his Doctorate from Tianjin University in 2005, and became a Professor in 2013. His current research interests focus on the nanoporous materials, electrocatalytic materials, amorphous alloys and biomedical metal materials.

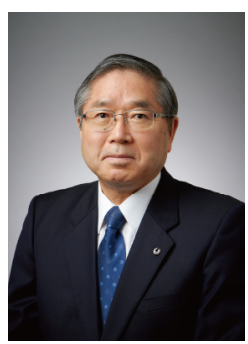

Akihisa Inoue is currently an Adjunct Professor at Tianjin University. He received his Doctorate from Tohoku University in 1975, and became a Professor in 1990. His current research interests focus on the amorphous metal, nanocrystalline metal and bulk metallic glass materials.

\section{双相纳米结构化可实现纳米多孔金属的优异柔性} 与综合力学性能

王超洋 ${ }^{1}$, 李章溢 ${ }^{1}$, 朱胜利 ${ }^{1,2,4^{*}}$, 梁砚琴 ${ }^{1,2}$, 崔振铎 ${ }^{1}$, 吴水林 ${ }^{1,2}$, 秦春玲 ${ }^{3}$, 罗水源 ${ }^{4}$, 井上明久 ${ }^{1,5}$

摘要 纳米多孔金属的力学性能对其在柔性电子领域的应用具有 重要意义. 本文报道了一种高强度、高硬度、柔韧性好的纳米多 孔Cu@Zr-Cu-Al金属玻璃( $\mathrm{NP} \mathrm{Cu} @ \mathrm{Zr}-\mathrm{Cu}-\mathrm{Al} \mathrm{MG}$ )复合材料, 该材 料采用两步脱合金法合成. 首先, 从 $\mathrm{Cu}_{46} \mathrm{Zr}_{23.5} \mathrm{Y}_{23.5} \mathrm{Al}_{7}$ 合金的伪二元 MG体系 $\left(\mathrm{Zr}_{47} \mathrm{Cu}_{46} \mathrm{Al}_{7} \mathrm{MG}+\mathrm{Y}_{47} \mathrm{Cu}_{46} \mathrm{Al}_{7} \mathrm{MG}\right)$ 中选择性蚀刻活性富 $\mathrm{Y}$ 的MG相, 制备了柔性纳米多孔Zr-Cu-Al金属玻璃(NP $\mathrm{Zr}-\mathrm{Cu}-\mathrm{Al}$ $M G)$. 进一步蚀刻得到 $N P \mathrm{Cu} @ Z r-C u-A l M G$, 其中 $\mathrm{Cu}$ 层均匀地覆

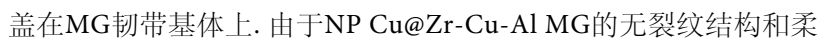
性Zr-Cu-Al MG 的存在, 使其具有良好的柔性. NP Cu@Zr-Cu-Al $\mathrm{MG}$ 的抗拉强度高达143.9 $\mathrm{MPa}$ ，纳米硬度高达0.79 GPa. Zr-Cu-Al MG强化相抑制了 $\mathrm{Cu} @ \mathrm{Zr}-\mathrm{Cu}-\mathrm{Al}$ 韧带的断裂, 有效抑制了裂纹在 NP $\mathrm{Cu} @ \mathrm{Zr}-\mathrm{Cu}-\mathrm{Al} \mathrm{MG}$ 中的萌生和扩展, 提高了复合材料的综合力学性 能. NP Cu@Zr-Cu-Al MG 可直接用作超级电容器和葡萄糖生物传 感器的电极, 比纯NP $\mathrm{Zr}-\mathrm{Cu}-\mathrm{Al}$ MG电极展现出更好的电导率和超 电容容量. 